\title{
The estimation of machining results and efficiency of the abrasive electro-discharge grinding process of Ti6Al4 V titanium alloy using the high-frequency acoustic emission and force signals
}

\author{
Pawel Sutowski $^{1}$ (D) $\cdot$ Robert Święcik $^{2}$
}

Received: 25 May 2017 / Accepted: 17 August 2017 / Published online: 26 August 2017

(C) The Author(s) 2017. This article is an open access publication

\begin{abstract}
The paper presents the results obtained for abrasive electro-discharge grinding (AEDG) of Ti6Al4V titanium alloy with the use of super hard grinding wheels of cubic boron nitride with a metal bond. The experimental investigations were focused on process monitoring for sharp and worn grinding wheels. For the evaluation of the grinding process, the grinding force amplitude and a few descriptors of the high-frequency stress waves were investigated in both time and frequency domains. The results show that during the AEDG, specific elastic waves are generated. Since these waves have characteristic amplitudes, frequencies, and other different descriptors dependent on the current grinding wheel cutting ability and discharge parameters, they can be applied to estimate a statistically significant regression function. For each measurement signal, a few statistical features are calculated and used as input for data selection and classification procedures. Registration and classification of forces and acoustic emission signals can be used to analyse the abrasive electro-discharge grinding process and allow for the determination of the machining results and the lifespan of super hard grinding wheels.
\end{abstract}

Paweł Sutowski

pawel.sutowski@tu.koszalin.pl

Robert Święcik

robert.swiecik@p.lodz.pl

1 Mechanical Department, Koszalin University of Technology, 15-17 Racławicka Str, 75-620 Koszalin, Poland

2 Institute of Machine Tools and Production Engineering, Lódź University of Technology, 1/15 Stefanowskiego Str, 90-924 Łódź, Poland
Keywords Acoustic emission · Abrasive electro-discharge grinding · Grinding wheel wear · Grinding forces $\cdot$ Statistical classifiers

\section{Introduction}

Performance and efficiency of grinding is affected by the selected conditions, processing parameters, and the condition of the active surface of the grinding wheel, which determines the ability to remove the machining allowance.

Grinding wheel wear is an important factor having effect on grinding in the manufacturing process of engineered parts and tools. When a wheel is worn, redressing is necessary. The lifespan of the grinding wheel and final surface properties of the workpiece are directly affected by grinding forces and the operating cutting temperature (i.e. in $[1,2]$ ).

Another problem is the properties of materials and their machinability, especially in the case of difficult-to-machine materials like titanium, nickel alloys or ceramics.

Veiga et al. made a review of the influence of titanium properties on its machinability. Titanium alloys present low grindability due to low thermal conductivity (heat generated by the cutting action does not dissipate quickly, and therefore most of the heat is concentrated in a small area of contact between grains and the material), high chemical reactivity (titanium has a strong alloying tendency and reactivity with abrasive grains at tool operating temperatures, which results in clogging of the grinding wheel active surface), low elastic modulus (the workpiece tends to move away from the cutting edges unless heavy cuts are maintained), high hardness and strength at elevated temperatures (titanium alloys require high cutting forces, which results in deformation on the cutting edges during machining process) and peculiar work hardening features (high loads per unit area coupled with the friction 
developed by the chip as it passes over the cutting area result in a great increase in heat, which is slowly conducted away by titanium and which can result in grinding burns on the workpiece surface) [3].

Preventing the unwanted phenomena in grinding of titanium alloys is possible by improving the process, e.g. by carrying it out at lower cutting speed and depth of cut [4]; supervision of the machining process, i.e. by monitoring grinding power, temperature [5] or force [6]; use of the grinding wheels with diamond [7], cubic boron nitride (CBN) (i.e. [8, 9]), silicon carbide ( $\mathrm{SiC})$ (i.e. [10] or [11]) or microcrystallinesintered corundum $\left(\mathrm{SG}^{\mathrm{TM}}\right)$ grains [12]; use of impregnated wheels (e.g. when impregnating with non-metallic elements [13] or sulphurized grinding wheels [14]; use of unconventional grinding fluids [15]; use of internal cooling [16]; grinding under MQL conditions [17] or hybrid processes (e.g. abrasive electro-discharge grinding [18] or ultrasonic-assisted grinding [19].

The main purpose of this work is to verify and investigate the sensitivity of acoustic emission signal in hybrid grinding process (i.e. classify abrasive electro-discharge grinding process), predict metal bond grinding wheel wear phenomena and correlate signals with machining results.

\section{Background and motivation}

The main motivation to obtain experimental base for inprocess monitoring of titanium grinding were poorly recognised diagnostic problem of super hard grinding wheel wear in the abrasive electro-discharge grinding (AEDG) process and the lack of knowledge if the diagnostic process can be effectively performed when an abrupt electrical discharge (electric spark) occurs.

The below subsections briefly describe some titanium alloy grinding problems and a few solutions proposed by several researchers.

\subsection{Grinding wheel wear and process forces}

Grinding of some titanium alloys can be very difficult due to grinding wheel wear and the high level of tangential force and specific energy values. The grinding forces (normal and tangential component of grinding force) play a significant role in quantitative analysis of grinding performance.

Razavi et al. studied the indentation model using force control grinding of gamma titanium aluminide (TiAl- $\gamma$ ) [20]. The authors used diamond, cubic boron nitride $(\mathrm{CBN})$ and aluminium oxide $\left(\mathrm{Al}_{2} \mathrm{O}_{3}\right)$ abrasives. Experimental data confirm both a proportional relationship between normal and tangential forces and a first-order relationship between the material removal rate (MRR) and the normal force $\left(F_{n}\right)$ (Fig. 1).

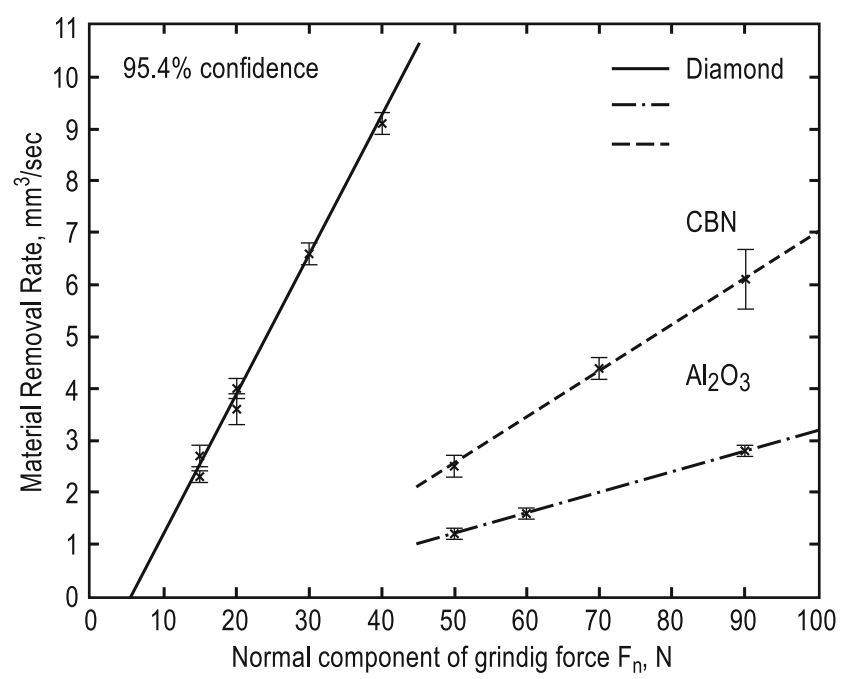

Fig. 1 Relationship between the material removal rate and the normal force for three different grinding wheels in TiAl- $\gamma$ grinding process. Note: diamond and CBN abrasives of grit size $120 / 140$ with $60 \%$ nickel coating, bonded with a phenolic resin, and $\mathrm{Al}_{2} \mathrm{O}_{3}$ abrasives of grit size $120, \mathrm{~K}$ hardness and a vitrified bond [20]

In the grinding process, it is basically reasonable to expect that there is a correlation between the grinding wheel wear and material grindability. Many methods are available to determine the grinding wheel wear and life, e.g. dramatic change of the grinding force or adhesion of the workpiece material to grinding wheel grains [14]. Both minor smearing (clogging areas) of a single abrasive grain and major smearing of grain groups with irregular shapes were pointed out during experiments (Fig. 2).

Zhang et al. found that grinding forces are relatively stable when the grinding wheels are sharp [12]. When the $\mathrm{SiC}(\mathrm{GC})$ wheel is dull, the normal force increases sharply while the tangential grinding force increases

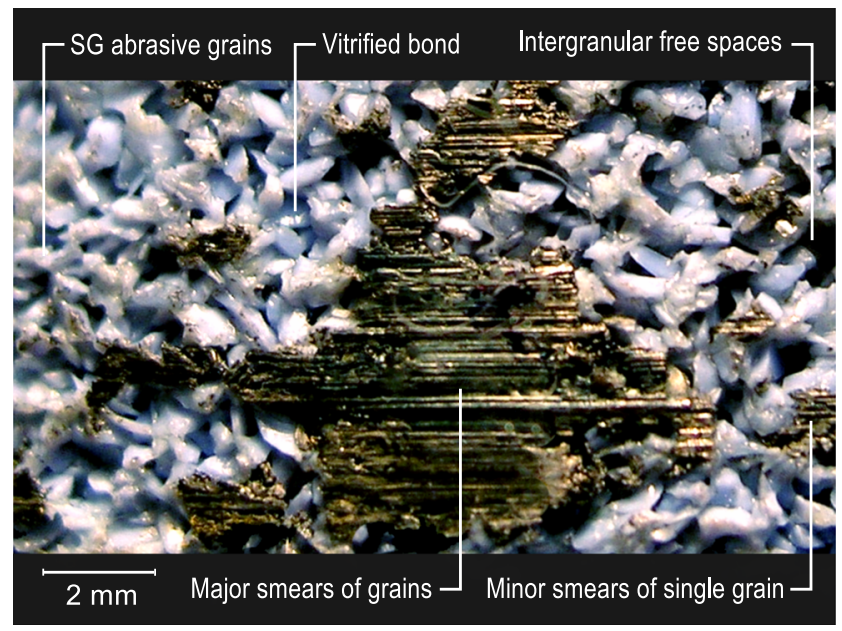

Fig. 2 Macrophotography of smeared active surface of the grinding wheel with microcrystalline-sintered corundum abrasive grains [14] 
slightly; therefore, the apparent jump of the force ratio $F_{n} / F_{t}$ is observed. In the case of the SG wheel, both normal and tangential grinding forces are dramatically reduced when the grinding wheel becomes dull. At the same time, the surface roughness deteriorates and radial wear of the wheel rapidly increases (Fig. 3).

$\mathrm{Xu}$ et al. analysed wear mechanism of three grinding wheels (made of $\mathrm{Al}_{2} \mathrm{O}_{3}, \mathrm{SiC}$ and $\mathrm{CBN}$, respectively) in Ti6A14V titanium alloy grinding process [10]. SEM micro-observations of the active grinding wheel surface indicated that adhering Ti6Al4V material can be seen on $\mathrm{SiC}$ grits when the machining temperature is raised up to $1000{ }^{\circ} \mathrm{C}$. The adhering material was also found on the $\mathrm{CBN}$ wheel when the temperature was increased up to $1300{ }^{\circ} \mathrm{C}$. The authors made a chemical analysis of the wear mechanism. In effect, they declared that $\mathrm{Ti}$ may actively react with $\mathrm{O}_{2}$ :

$\mathrm{Ti}+\mathrm{O}_{2} \rightarrow \mathrm{TiO}_{2}$.

The titanium oxide subsequently reacts with the $\mathrm{Al}_{2} \mathrm{O}_{3}$ grits, thereby leading to a strong bonding between the grit and the workpiece:

$\mathrm{Al}_{2} \mathrm{O}_{3}+\mathrm{TiO}_{2} \rightarrow \mathrm{TiO}_{2} \quad \mathrm{Al}_{2} \mathrm{O} 3$.

For $\mathrm{SiC}$ grinding, chemical reactions may cause interface diffusion between $\mathrm{SiC}$ grits and Ti6Al4V:

$\mathrm{SiC}+\mathrm{O}_{2} \rightarrow \mathrm{SiO}_{2}+\mathrm{C}$.

Then, the carbon from the abrasive reacts with $\mathrm{Ti}$ in the workpiece:

$\mathrm{Ti}+\mathrm{C} \rightarrow \mathrm{TiC}$.

Experimental results showed that much fewer workpiece materials were purely physically adhering to the $\mathrm{CBN}$ wheels, what seemed to indicate that chemical activity is not the dominant factor in the CBN grinding.

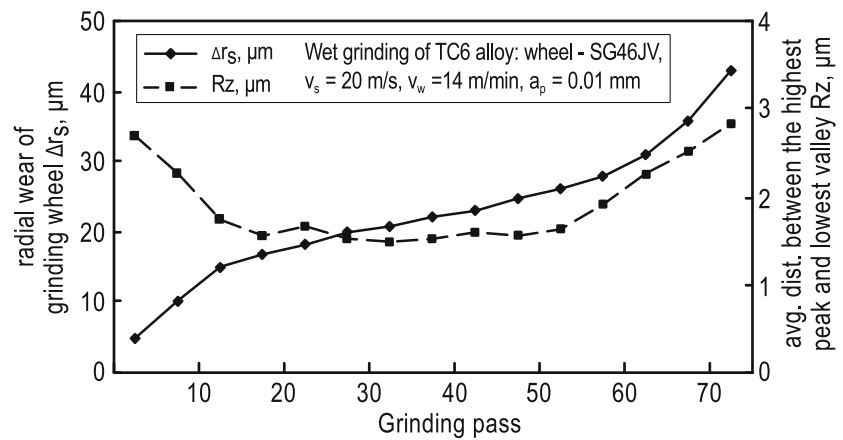

Fig. 3 Wear characteristic of a SG46JV grinding wheel — radial wear and roughness parameter for TC6 titanium alloy. [12]

\subsection{Abrasive electro-discharge grinding}

With the increased application of titanium alloys (particularly in aerospace applications), the ability to produce products with high productivity becomes challenging.

The electrical discharge machining (EDM) process, also known as spark machining, uses electrical current which generates electric sparks between the cathode (tool) and anode (workpiece), both submerged in a dielectric bath. The thermal energy leads to intense heat flow into the workpiece causing local melting and evaporation of the material, but at the end of the pulse on-time, some remaining liquid material re-solidifies - this re-solidified layer is referred to as the "white layer" [21]. The surfaces are complex, covered with craters, spherical particles, and melted drops (Fig. 4).

Niemczewska-Wójcik reports that with the increase in the energy of a single pulse, the surface topography changesboth building-up and craters, depressions and spheroids increase in size. The defect surfaces can be finished, for instance, manually. However, such processing requires high skills and is time consuming [22].

For these reasons, finding a more effective machining method is necessary.

In the AEDG process, removal of successive layers of the material is carried out using a metal-bonded grinding wheel, and the inter-electrode space is filled with a dielectric. The

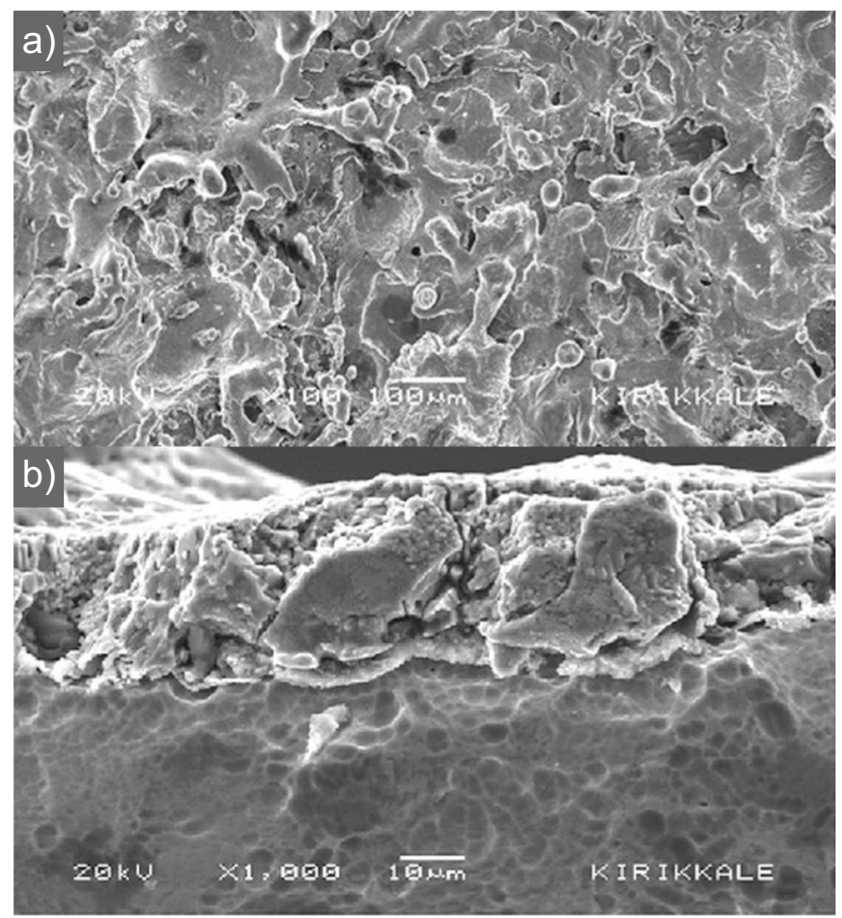

Fig. 4 SEM micrographs of Ti6Al4V surface machined by EDM process. a Top view of the surface with $R a=4.25 \mu \mathrm{m}$. b Crosssectional view showing the white layer. Note: discharge current $12 \mathrm{~A}$, pulse duration $100 \mu \mathrm{s}$, pulse interval duration $25 \mu \mathrm{s}$, dielectric Kerosene, dielectric flashing pressure $1 \mathrm{MPa}$, electrode material copper [21] 
mechanism of machining allowance removal results from the synergy of electric discharges (occurring between the grinding wheel and the workpiece surface) and mechanical cutting by active grains (Fig. 5).

The synergy of mechanical energy and electric sparks appearing in this process significantly affects the effectiveness and efficiency of grinding of difficult-to-machine materials. One of the most widely used EDM models are illustrated by Gatto et al.- the paper establishes very well mathematical grounds for the machining energy employed at each discharge event [24].

With the use of AEDG, the productivity of the process can be significantly improved. Comparison of the results of machining by conventional grinding with those obtained by means of the AEDG process was presented by Święcik [18]. The increase in the efficiency of the process is often obtained at the expense of low quality of the surface. Święcik focused on determination of AEDG process results related to forming of the geometrical texture of the surface in comparison to conventional grinding. Experiments focused on grinding of Ti6Al4V titanium alloy proved that AEDG yields worse (i.e. slightly higher) parameters of roughness and wavy finish as compared to the conventional grinding.

Kumar Singh Yadav et al. presented electrical discharge diamond grinding (EDDG), which integrates diamond grinding and electro-discharge machining (EDM) as a hybrid machining process for shaping electrically conductive very hard materials. The level of the optimal machining parameters on the MRR was determined by using Taguchi's method and analysis of variance (ANOVA). The authors indicated that MRR increase with increasing process parameters (current, wheel speed, and pulse on time) and decreases with the high surface finish mode of EDM. The MRR increase with increasing current (for a constant speed), because more discharge energy is released and the workpiece becomes thermally soft and hence easily removed by diamond grains. MRR increase with increasing pulse on time, because the fact that enough time is available for conduction of heat into the interior of workpiece - resulting in higher protrusion height and hence higher depth of penetration (MRR is related to the depth of penetration) [25].

Kozak investigated the material removal rate for a metalmatrix composite Duralcan F3S.20S (composite of aluminium alloy 359 and 20\% of SiC particles) and Compax 1600 Polycrystalline Diamond material using copper-based metalbonded diamond wheel [26]. The effect of machining time on MRR is presented in Fig. 6.

During conventional grinding, the wheel loses its cutting ability and the material removal rate decreases. After $10 \mathrm{~min}$ of grinding, the MRR decreases to one half of the initial value $(0.093 \mathrm{~g} / \mathrm{min})$. At the end of the 68 -min experiment, the material removal rate equals one fourth of the initial MRR. In the
Fig. 5 Schematic diagram illustrating the interaction between the grinding wheel and the workpiece in the AEDG process (according to [21, 23])

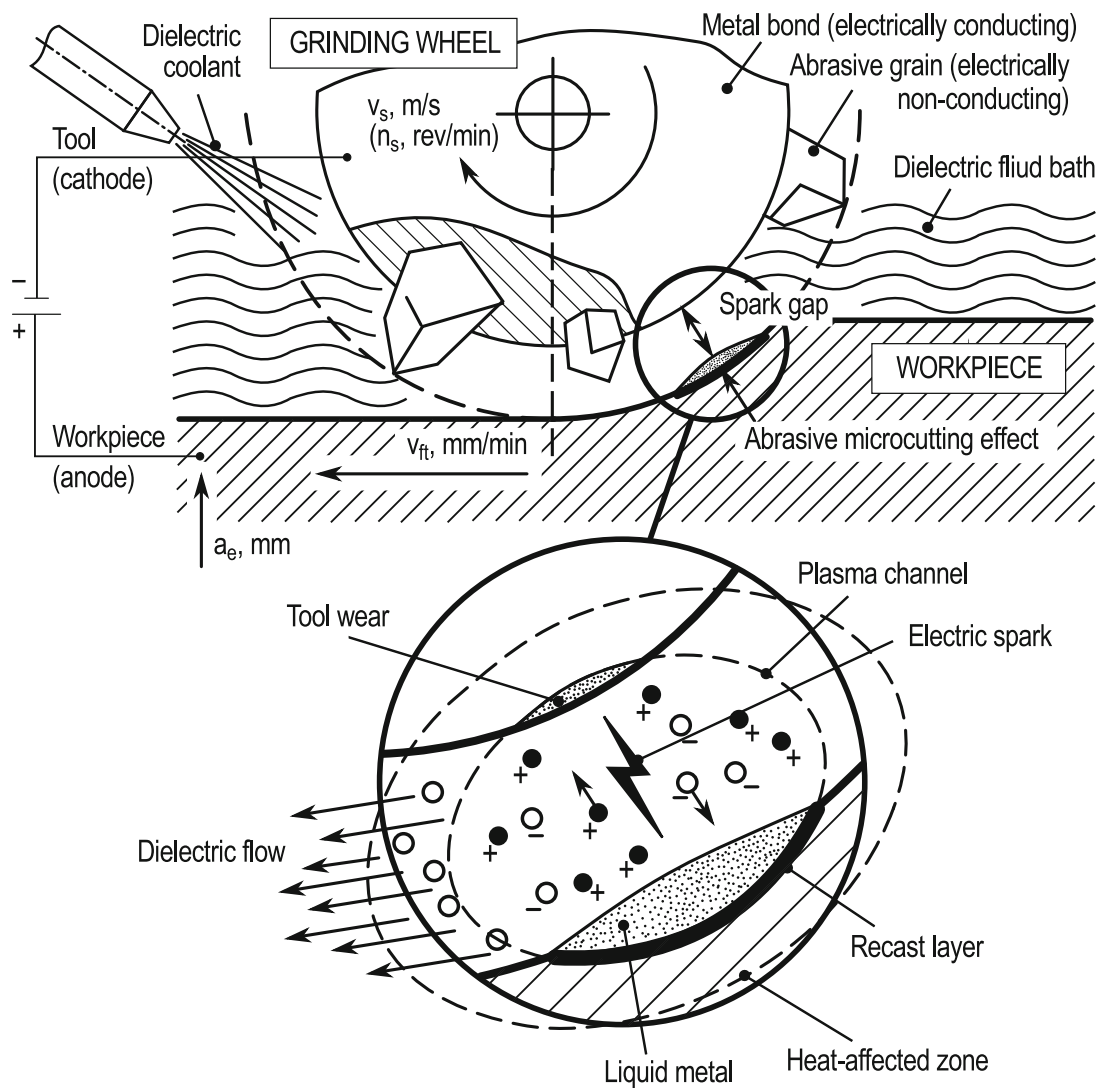




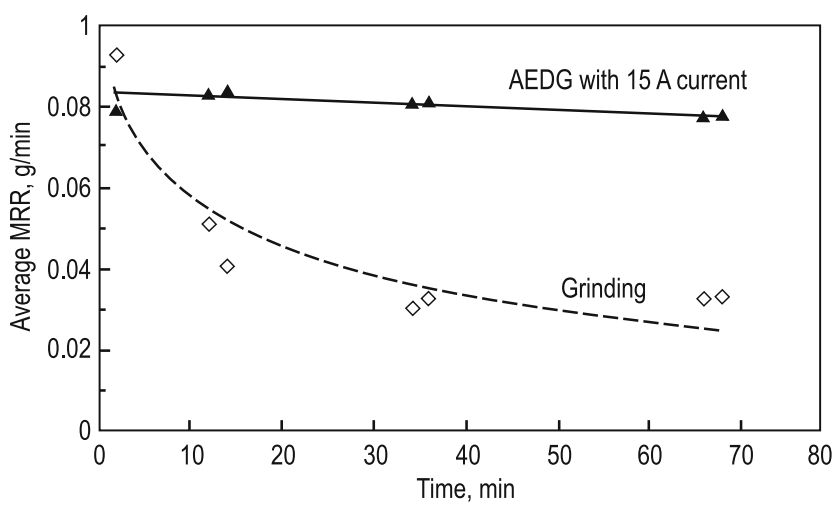

Fig. 6 Effect of machining time on MRR for Duralcan F3S.20S material. Note: speed $=4000 \mathrm{rpm}$, pulse on time $=60 \mu \mathrm{s}$, duty factor $=0.5$, grit size $=320[26]$

case of experiments with AEDG, the material removal rate is almost constant (approx. $0.08 \mathrm{~g} / \mathrm{min}$ ) throughout the experiment. This constant (MRR) can be attributed to the selfdressing effect [26].

In spite of these disadvantages, the performance of the AEDG is much greater than of the conventional grinding.

\subsection{Acoustic emission}

To properly implement grinding processes of titanium alloys, obtain information about the grinding wheel life as well as predict the quality of the workpiece or ensure repeatability for continuous production, it may be necessary to monitor and supervise machining process using different types of output signals (e.g. vibrations, noise, temperature, force or power).

The most often monitored factor is the grinding force, which is the most important output factor in evaluating the performance of grinding and can be monitored by piezoelectric sensors easily.

The forces in surface grinding have three components, i.e. tangential $F_{t}$, normal $F_{n}$ and feed grinding force $F_{f}$. However, $F_{f}$ is insignificant in the considered processes and thus can be neglected. An increase in $F_{n}$ increases the temperature in the grinding zone and changes the material removal mechanism from ploughing to chip formation [27].

Acoustic emission (AE) is a common tool used to monitor events occurring during various processes, including grinding process. Sutowski et al. presented a possible diagnostic method to be applied in the abrasive waterjet machining [28]. The authors confirmed the clear influence of machining conditions on the geometric structure of the obtained cuts and the registered values of the emitted high-frequency stress waves. Another example is the cylindrical grinding processes [29], where non-contact, Schall-Emissions-Hydrophon (SEH) sensors and monitoring SEM units are used. The parameters describing the $\mathrm{AE}$ impulse indicate the intensity and nature of phenomena in the grinding area, and therefore allow for the observation of the active acoustic wave sources [30]. Acoustic emission signal can be an input quantity for expert system and can be used to the evaluation of grinding wheel wear [31] or can be a convenient indicator for evaluation of stresses cumulated in the surface layer of the workpiece or can be used to evaluate selected surface geometrical structure parameters [32]. Kwak and Ha used peak values of AE and FFT parameters as the inputs of the neural network to diagnose the grinding faults, such as the chatter vibration and the grinding burn, but the maximum successful diagnosis (ca. 95\%) was obtained only for multi-sensor method (with acoustic emission sensor and power meter applied together) [33].

In the AEDG process, in addition to the typical grinding process AE sources, electrical discharges are observed. They can be clearly seen in the spectrum of the signal registered for electrical discharge systems [34]. Figure 7 shows the spectrogram corresponding to the exemplary AE signal generated by partial discharge multi-source system.

Grinding of titanium, even with newly developed grinding tools or methods, is still difficult due to chemical interaction between the workpiece material and the grinding wheel. Thus, it is believed that acoustic emission signal sensing would be a successful method to monitor and diagnose the abrasive electro-discharge grinding process.

\section{Experimental setup and procedure}

A series of grinding tests was conducted using metal-bonded grinding wheel with CBN grains and titanium alloy workpieces.

Experimental studies were aimed at monitoring the AEDG grinding process by means of analysing emission of the highfrequency stress waves and forces occurring in the machining zone. For comparison and statistical purposes, the studies were carried out in different conditions and repeated five times.

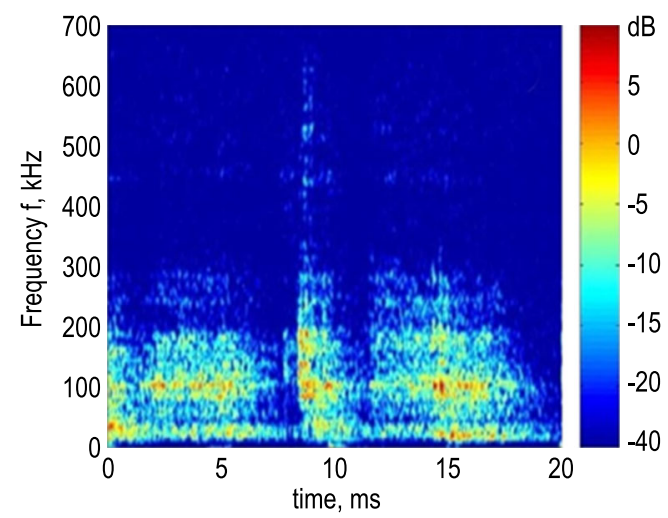

Fig. 7 Two-dimensional spectrograms of AE signals for multi-source partial discharges (with the use of the spark-gap point-point and surface form) [34] 


\subsection{The material and the grinding wheel}

Cube-shaped samples of Ti6Al4V titanium alloy (TC4 for China, AB-1 for USA and BT6 for Russia grade) of an approximate size $40 \times 24 \times 8 \mathrm{~mm}$ were used as workpieces. To minimise flatness and parallel deviation of surfaces, the workpieces were prepared by means of planarzing the surfaces in the conventional grinding process.

The chemical composition and mechanical properties of titanium alloy according to ASTM F1108 (cast material) are presented in Tables 1 and 2, respectively.

Experimental studies were conducted using metal-bonded straight grinding wheels with cubic boron nitride grains: 1$200 \times 75 \times 25$-CBN125/100 M75). The scope of tests included monitoring of the grinding process in the case of both sharp and worn active surface of the grinding wheel, allowing providing the basis for estimation of the cutting ability depending on the acquired $\mathrm{AE}$ signal.

The grinding wheels used in the experiments were used in preliminary grinding tests, both conventional and AEDG processes, of various difficult-to-cut materials (mainly titanium alloys). The methodology of grinding wheel preparation did not strictly specify the required volume of the removed material, but only the condition of a significant difference in the wear level of the active surfaces of wheels was determined. The grinding wheel considered as sharp took part in shortterm grinding processes. Based on the radial wear of the wheel, it was found that this wear was relatively small, and the grinding wheel has high cutting ability. By contrast, the grinding wheel marked as worn participated in long-term grinding trials. In this case, characteristic wear zones (significant abrasion loss) appeared on the active surface of that grinding wheel. The evaluation of wear level of both wheels is disused below.

The wear zone for both grinding wheels determined based on of the roughness profilograms, obtained for the crosssection of the active surface, is shown in Fig. 8.

A wheel with a high degree of wear has much higher amplitude parameters in the primary profile. The arithmetic mean deviation of the profile $(P a=25 \mu \mathrm{m})$ obtained for a dull wheel is almost twice higher than the one measured for a sharp wheel $(13 \mu \mathrm{m})$ while the difference in total height of the profile along the evaluation length is $34 \mu \mathrm{m}(P t)$. Moreover, the average

Table 1 The chemical composition of machining material-titanium alloy Ti6Al4V (Grade 5), wt.\% [35]

\begin{tabular}{llll}
\hline Carbon, $\mathrm{C}$ & Iron, Fe & Aluminium, Al & Vanadium, V \\
\hline$<0.1$ & $<0.3$ & $5.5-6.75$ & $3.5-4.5$ \\
Nitrogen, $\mathrm{N}$ & Oxygen, $\mathrm{O}$ & Hydrogen, $\mathrm{H}$ & $\mathrm{Ti}$ \\
$<0.05$ & $<0.2$ & $<0.015$ & Balance \\
\hline
\end{tabular}

Table 2 Selected physical and mechanical properties of titanium Ti6Al4V (Grade 5), annealed (according to [35-37])

\begin{tabular}{ll}
\hline Density & $4.43 \mathrm{~g} / \mathrm{cm}^{3}$ \\
\hline Elastic modulus & $113.8 \mathrm{GPa}$ \\
Tensile strength & $895 \mathrm{MPa}$ \\
Hardness, Rockwell C & 36 \\
Poisson's ratio & 0.342 \\
Compressive yield strength & $970 \mathrm{MPa}$ \\
Shear modulus & $44.0 \mathrm{GPa}$ \\
Elongation at break & $14 \%$ \\
Melting point & $1604-1660{ }^{\circ} \mathrm{C}$ \\
Thermal conductivity & $6.70 \mathrm{~W} /(\mathrm{m} \cdot \mathrm{K})$ \\
Velocity of sound & $4.987 \mathrm{~km} / \mathrm{s}$ \\
\hline
\end{tabular}

distance between profile elements $(\mathrm{PSm})$ is three times higher for the dull wheel.

Differences in the geometry of active surfaces of grinding wheels result from the wear mechanism, to which the grinding wheel was subjected in the long-term use. The wheel wear originates from various elementary processes (e.g. fracture and attrition wear), but the origin of these processes is different from those in conventional grinding. At every impact of

a)

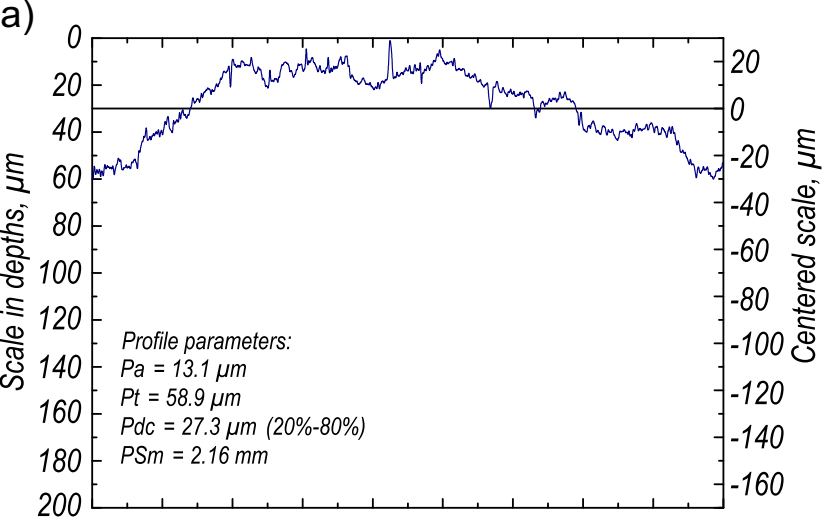

b)

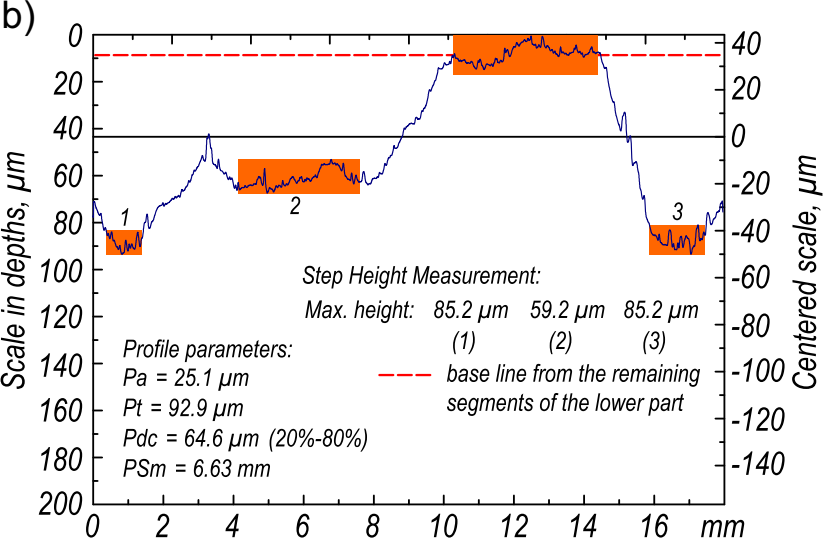

Fig. 8 Profiles presenting the cross-sections of active surfaces of the grinding wheels and wear in the case of a low wheel wear rate (sharp wheel) and $\mathbf{b}$ high wheel wear rate 
the electrical discharge, a small portion of the bond melts and vaporises. What is more, the area of contact between the wheel and the workpiece changes depending on the width of the workpiece. Hence, the irregular radial wear of the wheel, measured along the cross-section of the active surface, is observed. Therefore, the stair-like characteristics of the profile is visible (Fig. 8b).

The detailed description of the nature of wear of grinding wheels used in this study, including the assessment of the material removal rate and analysis of the grinding temperature, can be found in previous experimental works by Gołabczak et al., i.e. during comparative studies of the surface layer temperature in grinding process [38,39], cutting ability evaluation of grinding wheels [40] and research of temperature distribution in surface layer of titanium alloy workpieces [41].

\subsection{Machine set-up and experimental conditions}

All grinding experiments were performed with the use of a ECBT-8 surface grinder (Povazske Strojarne, Czechoslovakia), a GMP75 pulse generator of electrical discharges (Marcosta, Poland) and a measuring system composed of piezoelectric sensors and transducers from Kistler and National Instruments Corp. (Fig. 9).

In the study, the grinding force components and acoustic emission signal were investigated for surface grinding samples made of Ti6Al4V.

The scope of the research included an analysis of signals recorded for different cutting ability of metal-bonded grinding wheels with cubic boron nitride grains depending on various EDM parameters and constant grinding parameters (Table 3).

Variability of electrical discharges had a significant influence on the level of energy of a single pulse transmitted into the microcutting zone. A comparison of the values of energy of electric sparks, depending on the voltage and current, are presented in Table 4.

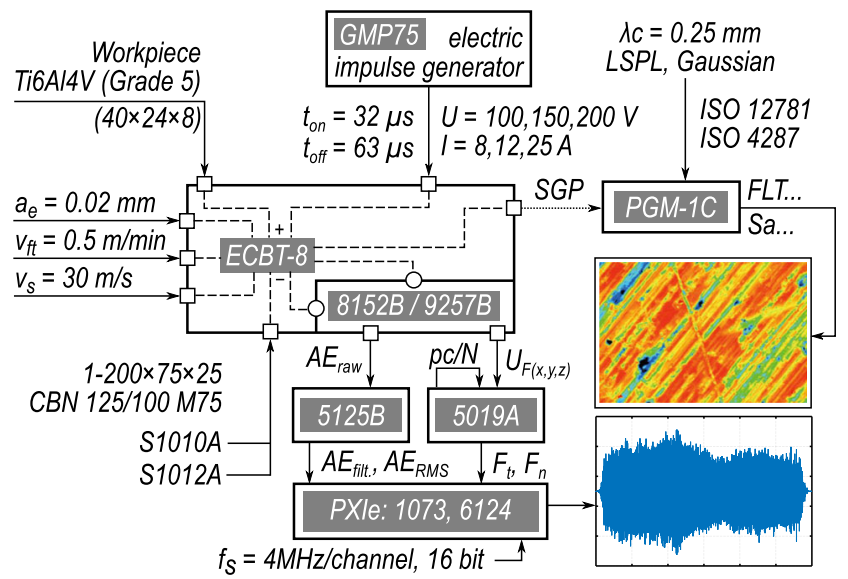

Fig. 9 Scheme of the experimental set-up
Table 3 List of parameters and test conditions

Grinding parameters (constant parameters)

\begin{tabular}{ll}
\hline Depth of cut $a_{e}(\mathrm{~mm})$ & 0.02 \\
Feed rate $v_{f t}(\mathrm{~m} / \mathrm{min})$ & 0.5 \\
Cutting speed $\mathrm{v}_{\mathrm{s}}(\mathrm{m} / \mathrm{s})$ & 30 \\
Lubricant & dielectric fluid (distilled water) \\
EDM parameters used for experimentation (variable parameters) \\
Working voltage $U(\mathrm{~V})$ & $100,150,200$ \\
Current $I(\mathrm{~A})$ & $8,12,25$ \\
Pulse time (on-time) $t_{\text {on }}(\mu \mathrm{s})$ & 32 \\
Pause time (off-time) $t_{\text {off }}(\mu \mathrm{s})$ & 63 \\
\hline
\end{tabular}

For comparison purposes, the grinding process was performed both with electrical discharges and without them (conventional grinding).

Considering the taken variation of conditions and parameters of the experimental study, the encoding was adopted, which corresponds to the strict conditions of the AEDG process. Table 5 presents ten different measurement points and their code marks.

\subsection{Forces and acoustic emission monitoring}

In the experimental studies, normal and tangential components of the grinding force and an acoustic emission signal were acquired from the grinding zone.

The grinding force generated by the interaction between the surfaces of the workpiece and the grinding wheel were detected and measured by a three-component piezoelectric dynamometer (9257B) and 5019A140 charge amplifier (Kistler Holding AG, Switzerland).

The acoustic emission signal measurement circuit was composed of a 8152B211 piezoelectric AE sensor and 5125B2 converter with $1.2-\mathrm{ms}$ integration time constant and high-pass $50-\mathrm{kHz}$ and low-pass $1000-\mathrm{kHz}$ filters (Kistler Holding AG, Switzerland). The 8152B sensor is highly sensitive to surface and longitudinal waves in a wide frequency range, i.e. from 100 to $900 \mathrm{kHz}$ (producer's data). These waves are transformed by the measurement system into

Table 4 The energy content of a single spark for selected electrical parameters of GMP75 pulse generator used in AEDG process

\begin{tabular}{lccc}
\hline $\begin{array}{l}\text { Generator parameters } \\
\text { Voltage } U(\mathrm{~V})\end{array}$ & Current $I(\mathrm{~A})$ & Power $P(\mathrm{~kW})$ & $\begin{array}{l}\text { The energy content } \\
\text { of a single spark } E_{s}(\mathrm{~J})\end{array}$ \\
\hline 100 & 8 & 0.8 & 25.6 \\
150 & 12 & 1.8 & 57.6 \\
200 & 25 & 5.0 & 160.0 \\
\hline
\end{tabular}


Table 5 Encoding used in the analysis of experimental results

\begin{tabular}{|c|c|c|c|c|c|c|c|}
\hline \multirow[t]{2}{*}{ Sample code mark } & \multicolumn{2}{|c|}{ Wheel condition } & \multicolumn{2}{|l|}{ Lubricant } & \multicolumn{3}{|c|}{ Voltage and current } \\
\hline & Sharp & Worn & $\begin{array}{l}\text { None } \\
\text { (dry grinding) }\end{array}$ & $\begin{array}{l}\text { Dielectric } \\
\text { (distilled water) }\end{array}$ & $\begin{array}{l}\mathrm{U}=100 \mathrm{~V} \\
I=8 \mathrm{~A}\end{array}$ & $\begin{array}{l}\mathrm{U}=150 \mathrm{~V}, \\
I=12 \mathrm{~A}\end{array}$ & $\begin{array}{l}\mathrm{U}=200 \mathrm{~V} \\
I=25 \mathrm{~A}\end{array}$ \\
\hline S1010A-KS-000-00 & + & & + & & & & \\
\hline S1010A-KD-000-00 & + & & & + & & & \\
\hline S1010A-AE-100-08 & + & & & + & + & & \\
\hline S1010A-AE-150-12 & + & & & + & & + & \\
\hline S1010A-AE-200-25 & + & & & + & & & + \\
\hline S1012A-KS-000-00 & & + & + & & & & \\
\hline S1012A-KD-000-00 & & + & & + & & & \\
\hline S1012A-AE-100-08 & & + & & + & + & & \\
\hline S1012A-AE-150-12 & & + & & + & & + & \\
\hline S1012A-AE-200-25 & & + & & + & & & + \\
\hline
\end{tabular}

electric impulses with voltage output proportional to the energy of the excitation source.

The piezoelectric sensor was mounted on the bottom side of the workpiece (Fig. 10).

In order to isolate the sensor from electrical discharges, the fastening elements were made of plastic. The screw and the washer (plate) were made of a special dielectric materialtextolite. This material has relatively low sensitivity to elevated temperatures (it does not melt and does not change its shape under the influence of elevated temperatures and considerable pressure). With the fully cross-linked structure reinforced by a fabric, the material is characterised by high strength to forces
Fig. 10 Mounting scheme for a piezoelectric sensor for acquisition of acoustic emission signal from the grinding zone in the AEDG process. a Piezoelectric sensor (Kistler 8152B211) electrically isolated from electrical discharges. $\mathbf{b}$ Dynamometer (Kistler 9257B) with a clamp and a workpiece mounted to the grinding table a)

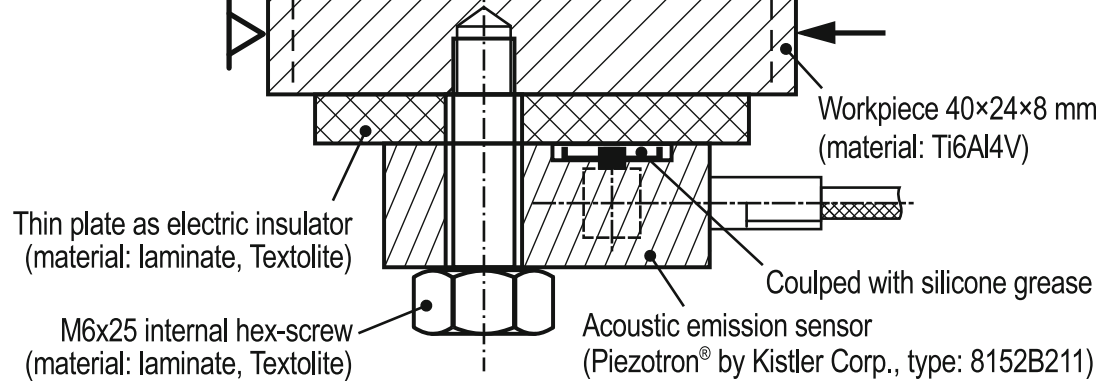

b)

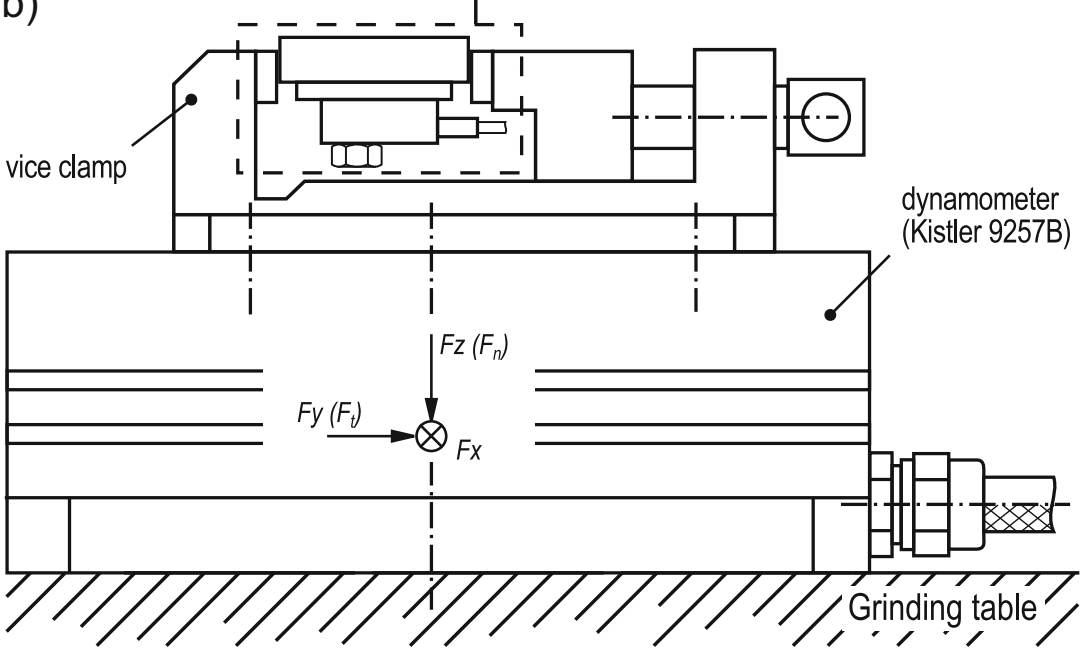


and impacts. The exact parameters of the textolite are defined in EN 60893-3-4:2004.

All signals were acquired using a modular PXIe-1073 DAQ system with 6124 multifunctional 16-bit converter (National Instruments Corp., USA) and sampled to digital form at the frequency $f_{s}=4 \mathrm{MHz}$ per channel. The described system allows one to avoid missing critical data by means of using high-quality acquire hardware which features highaccuracy analogue signal conversion and conditioning as well as precise timing for sensors and signals.

\subsection{Surface metrology}

The presented research results refer to the geometrical measurements of the surface microstructure of workpieces machined in the conventional and AEDG grinding processes.

The measurements of the surface roughness were executed in the 3D system by PGM-1C profilometer (IOS The Institute of Metal Cutting - The Institute of Advanced Manufacturing Technology from March 23th, 2005, Kraków, Poland). Geometrical surface parameters were investigated according to standards, i.e. ISO 12781 for flatness and ISO 4287/4288 for waviness and roughness after filtration with the Gaussian Filter (ISO 11562) and $0.25 \mathrm{~mm}$ cut-off value.

\section{Results and discussion}

In this section, the experimental results and their detailed description are presented. This section is divided into parts connected with the main goals of experimental studies related to the following topics: geometrical structure of the surface of titanium alloy workpieces after grinding in different process conditions (especially in the case of the AEDG process); the changes in the acoustic emission and force values during grinding and the correlation of output signals with the surface quality and grinding wheel wear, possibility of predicting tool wear and classifying the AEDG process by output signals.

\subsection{Geometrical microstructure of the surface}

TalyMap software (Tylor Hobson Precision Ltd., England) was used to study surface texture parameters. It calculates amplitude parameters ( $S a, S q, S z, S s k, S k u, V v c, V v v$ and $V m p)$ in accordance with the EUR $15178 \mathrm{EN}$ norm, and as extrapolations of the 2D parameters normalised according to the ISO 4287 standard (in the case of $S t, S p$, and $S v$ parameters). Parameters of the flatness of a surface (FLTt, FLTp, FLTv and FLTq) were calculated on the basis of a surface levelled by the least square method according to the ISO 12781 standard.

The changes in the total deviation from flatness (precisely: peak-to-valley flatness deviation of the surface, FLTt) for different grinding conditions are presented in Fig. 11. The results

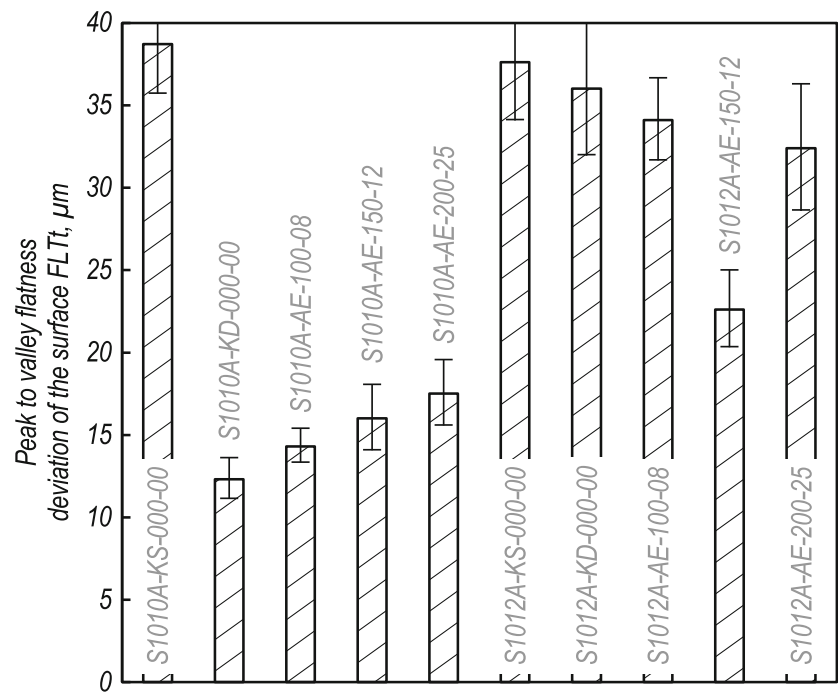

Fig. 11 The changes of the peak-to-valley flatness deviation of the surface $(F L T t)$ after grinding with the CBN wheel under different conditions

of the measurements indicate that in most cases, the total deviation from flatness is doubled (from level of about $15 \mu \mathrm{m}$ to level of greater than $30 \mu \mathrm{m}$ ), when the worn grinding wheel is used.

In the case of grinding with a sharp grinding wheel (S1010A series), the total deviation from flatness increases gradually and insignificantly, but the increase becomes clearly noticeable when higher energy of discharges is delivered to the grinding zone. Only the first case (grinding without the cooling fluid, S1010A-KS-000-00) is an exception, and $F L T t=38.6 \mu \mathrm{m}$.

During the conventional dry grinding tests (with parameters presented in Table 3), no grinding burns were observed on the surface of the workpieces. This can be explained by the use of grinding wheels with a metal bond, which removes part of the heat generated in the grinding zone. According to the results presented by Gołabczak in [41], in the case of dry grinding of Ti6Al4V titanium alloy, the average temperature in the machining zone is about $550-600{ }^{\circ} \mathrm{C}$. This temperature is much lower than the melting point of this alloy (Table 2). Only a few sections of grinding burns were observed on workpieces during AEDG grinding with the highest electrical discharge energy ( $U=200 \mathrm{~V}$ and $I=25 \mathrm{~A}$ ). In this case, the temperature of the top layer of Ti6Al4V alloy can exceed $1300{ }^{\circ} \mathrm{C}[38]$.

When grinding process is realised with a coolant (S1010AKD-000-00), the quality of surface increases - the FLTt value falls sharply to $12.3 \mu \mathrm{m}$. The introduction of electrical discharges into the grinding process increases the observed peakto-valley flatness deviation of the surface from $12.3 \mu \mathrm{m}$ (S1010A-100-08) to $14.3 \mu \mathrm{m}$ and more (cases S1010A-15012 and S1010A-200-25). 
In the case of using a worn wheel (S1012A series), the grinding process is under completely different conditions, what is reflected in relatively high values of FLTt parameter. The highest value $(F L T t=37.6 \mu \mathrm{m})$ is observed for the process carried out without the use of a coolant (S1012A-KS000-00). Even with the use of the coolant or the hybrid process with electrical discharges, flatness deviation of the surface stays at a high level (36 $\mu \mathrm{m}$ for grinding with coolant (for S1012A-KD-000-00) and from $22.6 \mu \mathrm{m}$ (for S1012A-AE$150-12$ ) to $34.1 \mu \mathrm{m}$ (for S1012A-KD-100-08) in the case of the AEDG process).

The AEDG process conducted with the same parameters, but with a worn wheel, always gives higher deviation from flatness. This is due to the significant radial wear of the grinding wheel.

The nature of changes in the basic height parameters characterising the surface roughness (e.g. arithmetic mean deviation of the surface $S a$ and the total height of the surface $S t$ ) are largely similar to surface flatness results. The parameter $\mathrm{Sa}$ (Fig. 12) in the case of conventional grinding (S1010A-KD$000-00)$ is $0.68 \mu \mathrm{m}$, and after introduction of electrical discharges into the process, it linearly increases from 1 to $1.4 \mu \mathrm{m}$ due to the energy of discharges.

In the case of grinding tests with the worn wheel (S1012A series), no significant tendency in the $S a$ parameter was observed. However, if one compares the results obtained for the same conditions for both sharp (S1010A series) and worn (S1012A series) grinding wheels, one can notice a decrease in roughness in the case of tests with the worn wheel. This is due to large differences in the geometry of the active surfaces of the compared grinding wheels. The worn wheel was characterised by significant stair-like profile, while the sharp wheel was devoid of these irregularities (it was free from radial wear) but had higher roughness (due to higher grain

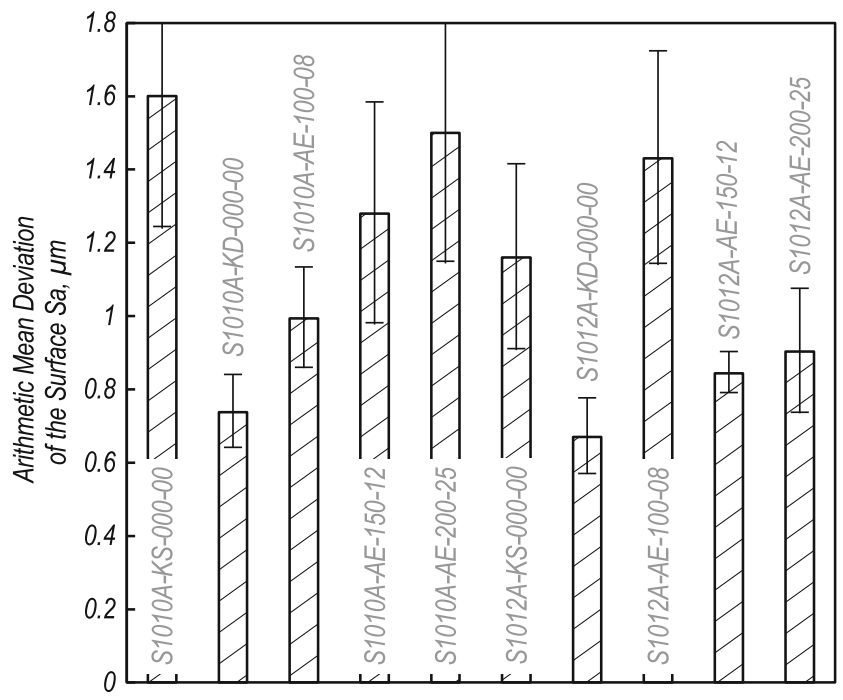

Fig. 12 The changes in the arithmetic mean deviation $(R a)$ of the surface after grinding using $\mathrm{CBN}$ wheel and different conditions

cutting edges without symptoms of attritious wear or fracture of grains, and air spaces (pores) without accumulated chips).

Figure 13 presents the microstructure of two surfaces after the AEDG process - the first for the use of the sharp grinding wheel (Fig. 13a) and the second one for the worn wheel (Fig. 13b). All other experiment conditions were constant, and the presented results were obtained for the highest electrical parameters $(U=200 \mathrm{~V}$ and $I=25 \mathrm{~A})$.

The AEDG grinding process with such electrical parameters apparently shows differences in the values obtained for the sharp and worn grinding wheels. However, due to the use of the same grinding wheels in all experiments, the presented results may be generalised for all cases - higher values of roughness and deviation were observed for surfaces ground with the worn wheel.

In fact, Fig. 13 presents results of an analysis of slices of the investigated workpiece surfaces. The slices have been obtained by means of segmentation using two thresholds (heights). The upper threshold is equivalent to the peak material ratio (Smrl parameter in the height characterisation using the linear material ratio curve) and separates the protruding hills from the core surface of the evaluation area. The part of the surface above this threshold comprises only small peaks. On the other hand, the lower threshold is equivalent to the valley material ratio $(S m r 2)$, which separates the protruding dales from the core surface.

The surface presented in Fig. 13b appears to be more uniform but actually has a larger deviation in the shape than the surface presented in Fig. 13a. Namely, a larger range of roughness amplitude is observed for the surface ground with the worn wheel.

a)

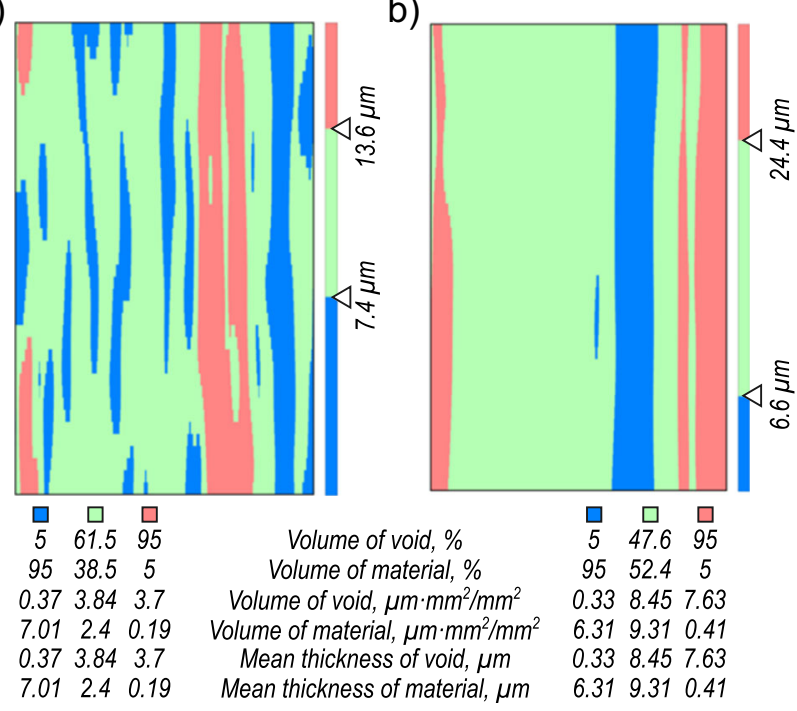

Fig. 13 The result of an analysis of slices between two threshold values for the titanium alloy surface after AEDG. a Surface representation after grinding with a sharp wheel (S1010A-AE-200-25). b Surface after grinding with a worn wheel (S1012A-AE-200-25) 
In the analysis, 95\% material ratios were assumed both for the valleys (voids) and the peaks (material). Namely, it was assumed that only $5 \%$ of the volume of material is left above the $S m r 1$ value, and only $5 \%$ of the volume of voids is present below the $S m r 2$. In this manner, important information on the volume fraction of three zones: the core surface, a zone of very high peaks and a zone of very deep valleys have been obtained.

The most significant changes can be observed in the peak and core areas. By comparing the results for wheels with different degrees of wear, it can be concluded that the volume of the empty space (void) and its height is more than doubled (from 3.7 to $7.63 \mu \mathrm{m}$ ) in the peak area (above the upper cut-off value) for the worn wheel. For the core, a significant increase in voids ( $V v c$, the void volume of the core section) is also observed, i.e. the average thickness of voids increases from 3.84 to $8.45 \mu \mathrm{m}$.

A significant decrease in the material ratio in the geometric structure of the surface, regardless of the analysed zone, clearly shows an increase in the surface roughness in the case of machining using grinding wheel with a higher degree of wear.

\subsection{Acoustic emission and force signals}

The set up for force and AE measurements exhibited effective sensitivity to the AEDG process, especially for detection of various conditions of the process and the occurrence of grinding wheel wear. When analysing the results of the research, changes in the amplitude of the recorded output parameters of grinding process were observed. Both components of the grinding force and the acoustic emission signal changed according to the machining parameters and different grinding wheel wear level (Figs. 14 and 15).

For a conventional grinding process (left column in Figs. 14 and 15), introduction of the coolant into the grinding zone reduces both the forces (Fig. 15) and registered AE signal (Fig. 14). In the case of the sharp wheel (S1010A series), normal component of force $\left(F_{n}\right)$ decreases from 300 to $100 \mathrm{~N}$ (Fig. 15a) and tangential component $\left(F_{t}\right)$ decreases from 175 to $70 \mathrm{~N}$ (Fig. 15b). For the same conditions, the registered amplitudes of $\mathrm{AE}$ signal $A E_{\text {filt. }}$ decrease from 1.9 to $1.3 \mathrm{~V}$, and the effective value of $\mathrm{AE}$ signal $\left(A E_{R M S}\right)$ decreases (from 4.5 to $3.2 \mathrm{~V}$ ) (Fig. 14) (S1010A series). Lower values of both output signals recorded in the grinding zone mean that the machining process proceeds under more favourable conditions, which is consistent with theory and practice.

For the worn wheel (S1012A series), the tendency is similar-values of measured forces and acoustic emission decrease when the coolant is added to the process. The mean value of the normal component of the grinding force $\left(F_{n}\right)$ changed from 600 to $320 \mathrm{~N}$ while the tangential component $\left(F_{t}\right)$ changed from 270 to $170 \mathrm{~N}$ (Fig. 15). For the same
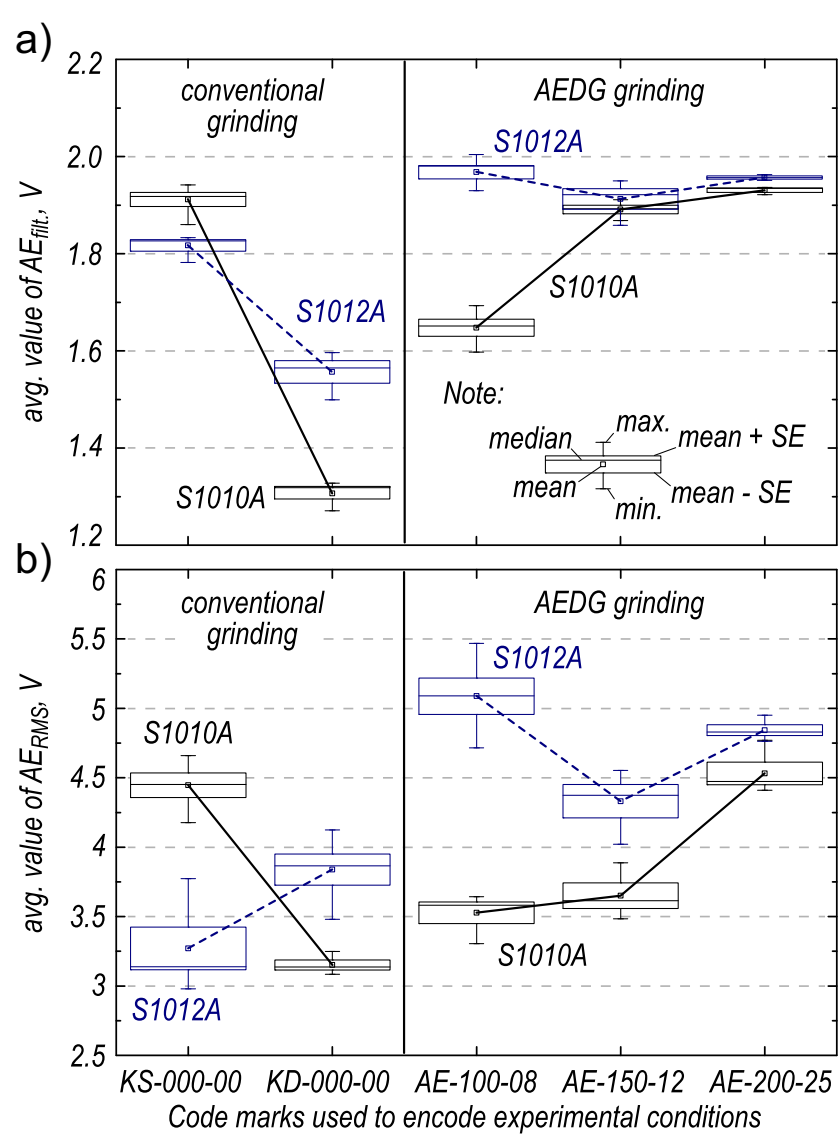

Fig. 14 The changes in the amplitude of the registered AE signals for different conditions of the grinding process. a Filtered acoustic emission signal $\left(A E_{\text {filt. }}\right)$. b Effective value of AE signal $\left(A E_{R M S}\right)$

process conditions, the mean value of amplitude of $\mathrm{AE}$ signal $\left(A E_{\text {filt. }}\right)$ decreased from 1.82 to $1.57 \mathrm{~V}$ (Fig. 14a).

The only exception to this rule was observed in the case of the RMS value of the signal AE (Fig. 14b). The statistical analysis of RMS indicated its increase - the mean value of $A E_{R M S}$ changed from 3.25 to $3.8 \mathrm{~V}$. In statistics, since the AE signal is zero-mean random signal (the mean signal is 0 ), RMS includes the "error" (square deviation) and can be interpreted as the standard deviation of the signal. Larger data scatter (higher RMS value of the signal) may indicate the process that takes place in adverse conditions. In the case of analysis of current from a defective machine, effective values are higher than in the case of an undamaged device (e.g. for monitoring of induction motor [42], rotor fault [43] or wind turbine gearboxes [44]). This relationship can be transferred to the grinding process, which is carried out with grinding wheels with different wear levels. The effective value of AE signal is higher $(3.8 \mathrm{~V})$ for the worn wheel compared to the sharp wheel (3.2 V) (Fig. 14b). Full explanation of this phenomenon, however, requires further research.

Generalising the results, the use of a wheel with a high degree of wear in a conventional grinding process (with the use of a coolant) increases the force in the contact zone and 


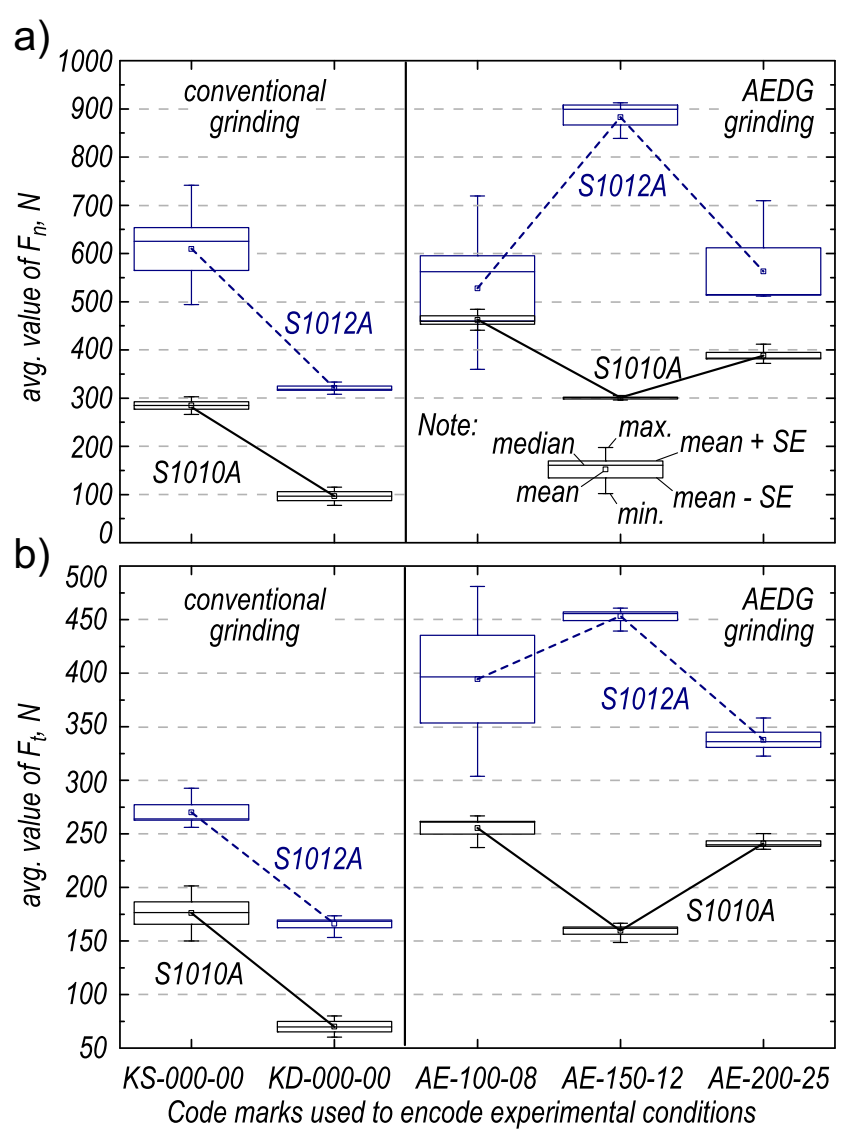

Fig. 15 The changes in the amplitude of the registered values of grinding force components for different conditions of the process. a Normal component of force $F_{n}$. b Tangential component of force $F_{t}$.

registered values of AE signal impulses. The results for AEDG process are discussed below.

When grinding is combined with electrical discharges (right column of Figs. 14 and 15), the output signals have higher values than for a conventional process. In the case of grinding force components (Fig. 15), it is well known that wear of grinding wheel leads to the increase in the observed values. The reason for this was the radial wear of the grinding wheel (caused by the increasing contact area of the grinding wheel with the workpiece), which reduced single grain load and decreases material removal efficiency.

The increase is clearly observed and proportional to the energy of discharges only in the case of the recorded $\mathrm{AE}$ signals for the sharp wheel (S1010A series) (Fig. 14). The observed tendency has a power functional relationship (for average value of $A E_{\text {filt. }}$ parameter) and exponential correlation (for average value of $A E_{R M S}$ parameter). The explanation of this phenomenon is the contribution of an additional factor (electrical discharges) in the grinding process, resulting in more $\mathrm{AE}$ impulse sources and higher values of the recorded signals.

A correlation between the electrical parameters of AEDG process and the recorded output signals, when using a worn grinding wheel (S1012A series), shows no unambiguous trends (except from the polynomial one, but no physical significance of such a behaviour can be distinguished).

The results for the AEDG process conducted with the worn wheel and the minimum energy of electric sparks (case S1012A-AE-100-08) present the highest values of AE signal in all experiments. This means that the introduction of electrical discharges into the grinding process caused generation of additional AE impulse sources with relatively high total energy. Therefore, high amplitude and energy of the AE signal (avg. $A E_{R M S}=5.2 \mathrm{~V}$ ) as well as high dispersion of the normal and tangential components of the grinding force are observed.

The highest average values of the grinding force components (Fig. 15), with simultaneous lowest AE signals (Fig. 14), for the worn wheel were obtained in the case of medium electrical parameters with $150 \mathrm{~V}$ and $12 \mathrm{~A}$ current (S1012AAE-150-12). The probable cause of increased force during the AEDG process could be the phenomenon of self-sharpening of the grinding wheel [45] or an increase in impulse force (deeper craters, with higher bulge height $h_{b u l}$ and recast depth $h_{\text {rec }}$, occurred thereby) $[46,47]$ as the effect of high electrical process parameters. However, at this stage of research, the analysis of this phenomenon went beyond the established range of tests.

For those process conditions, the decrease in energy of the AE signal took place (form 5.2 to $4.3 \mathrm{~V}$ ). As the energy of the electrical discharges increased, plastic deformation of the material increased (as a result of the increase in the temperature of the process), which makes it easier to remove the grinding material. The increased contribution of plastic deformation in relation to elastic deformation resulted in a reduced piezoelectric sensor response and, as a consequence, lower values of the AE signals recorded.

With the highest electrical parameters of the pulse generator (Fig. 15, case S1012A-200-25), the temperature increased to the point where the self-sharpening of grinding wheel was applied. The process efficiency increased (by erosion) and the grinding force decreased. A large amount of heat delivered to the grinding zone resulted in significant melting and evaporation of the material. Therefore, a decrease in pressure (decrease in the value of the normal component of the grinding force) and a reduction in the contact resistance of grain vertices with cutting material (decrease value of tangential component of the grinding force) were observed. A more detailed description of the research focused on electrical discharge energy, and the energy consumption in grinding process was presented in [18].

In the case of using high-energy electric sparks $(U=200 \mathrm{~V}$, $I=25 \mathrm{~A}$ ), the dominance of the EDM process over mechanical removal of the material can be marked by an increase in values of the AE signal (Fig. 14). In these conditions of machining, the energy of sparks is so large (exactly: $496.4 \mathrm{~J}$, according to research by Święcik presented in [18]) that there is an increase 
in the signal recorded by the sensor. Pulses of Rayleigh waves, detected by piezoelectric sensor, are generated by sparks and can carry about $50 \%$ of the energy of electric discharge [48, 49].

In the case of acoustic emission signal, the analysed descriptors can be divided into groups depending on the conditions used in the grinding process. This means that the $\mathrm{AE}$ signal processing can thereby be used to group the results into relatively homogeneous classes in an efficient way. This is due to the nature of the AE signal, which can be used as a tool for monitoring the dynamic events taking place in the machining zone.

The recorded acoustic emission signal (Fig. 16) significantly changes its characteristics depending on the type of the grinding process and the rate of grinding wheel wear.

Signal waveforms show that the sum of events and their rate significantly increase if the process takes place with the participation of the phenomena typical for a worn wheel. Referring the nature of the AE signal in the AEDG grinding process to conventional, a significant increase in signal noise is observed. This noise is associated with additional sources of $\mathrm{AE}$ impulses and can be considered as a result of electrical discharges.

AE signal spectra (Fig. 17) disclose a change in the volumes of the harmonics when the worn grinding wheel is involved in the process, regardless of the analysed frequency (in the range up to $1200 \mathrm{kHz}$ ). The statistical distribution of values observed in the power spectral density (PSD) for the representative frequency $(600 \mathrm{kHz})$ is shown in histograms (Fig. 17c, d). The shape of the PSD distribution represents gamma distribution with parameters dependent on the cutting ability of the wheel.

The character of changes is observed also in the case of arithmetic mean, standard deviation, variance, skewness and kurtosis distribution as well as adjusted sum of squares and the range (the difference between the largest and the smallest values). Some examples are presented in Table 6 and Fig. 18.

To explain trends in a more clear way, the radar charts are divided into half in Fig. 18. The right side of the graph represents the results for the sharp wheel, while the opposite side represents the results for the same process parameters, but for the worn grinding wheel. Each section of the radar graph represents different conditions. Looking from the top section (in a clockwise direction), the graphs present results for dry grinding, grinding with cooling and the three sections for AEDG process with increased power of electrical discharges.

Dependent on grinding process conditions, the registered values of PSD of acoustic emission signal are clearly changing, regardless of the use the sharp or worn wheel. A higher PSD level of the signal was always recorded for the worn wheel (S1012A series). This phenomenon can be explained by a higher degree of grindability of the grinding wheel, which has not been worn yet, and thus less resistance in the microcutting by abrasive grains, and consequently by lower energy of the acoustic emission sources.

For the conventional grinding process with a sharp wheel, the mean value of PSD rapidly decreases from $4.7 \mathrm{~W} / \mathrm{Hz}$ (S1010A-KS-000-00) to $0.5 \mathrm{nW} / \mathrm{Hz}$ (S1010A-KD-000-00), when coolant is added into the machining. The coolant plays a very important role in the grinding process, especially in the
Fig. 16 AE signals registered in the grinding process under different conditions. a S1010AKD-000-00. b S1012A-KD-00000. c S1010A-AE-150-12. d S1012A-AE-150-12 a)
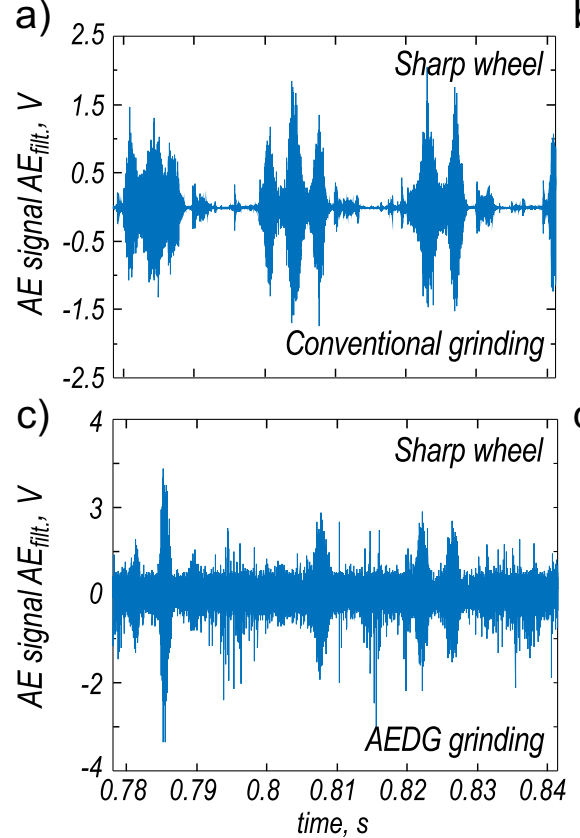

b)

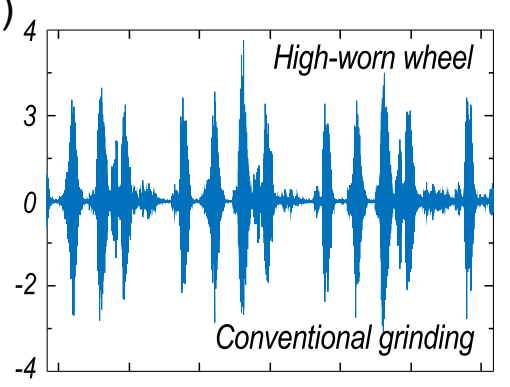

d)

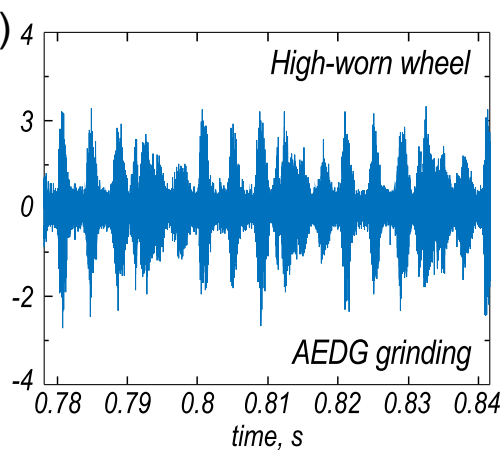


Fig. 17 Spectrograms of the acoustic emission signal for the AEDG process. a Sharp wheel (S1010A-AE-150-12). b Worn wheel (S1012A-AE-150-12). The example of the distribution of the power spectral density for 600 kHz. c S1010A-AE-150-12. d S1012A-AE-150-12

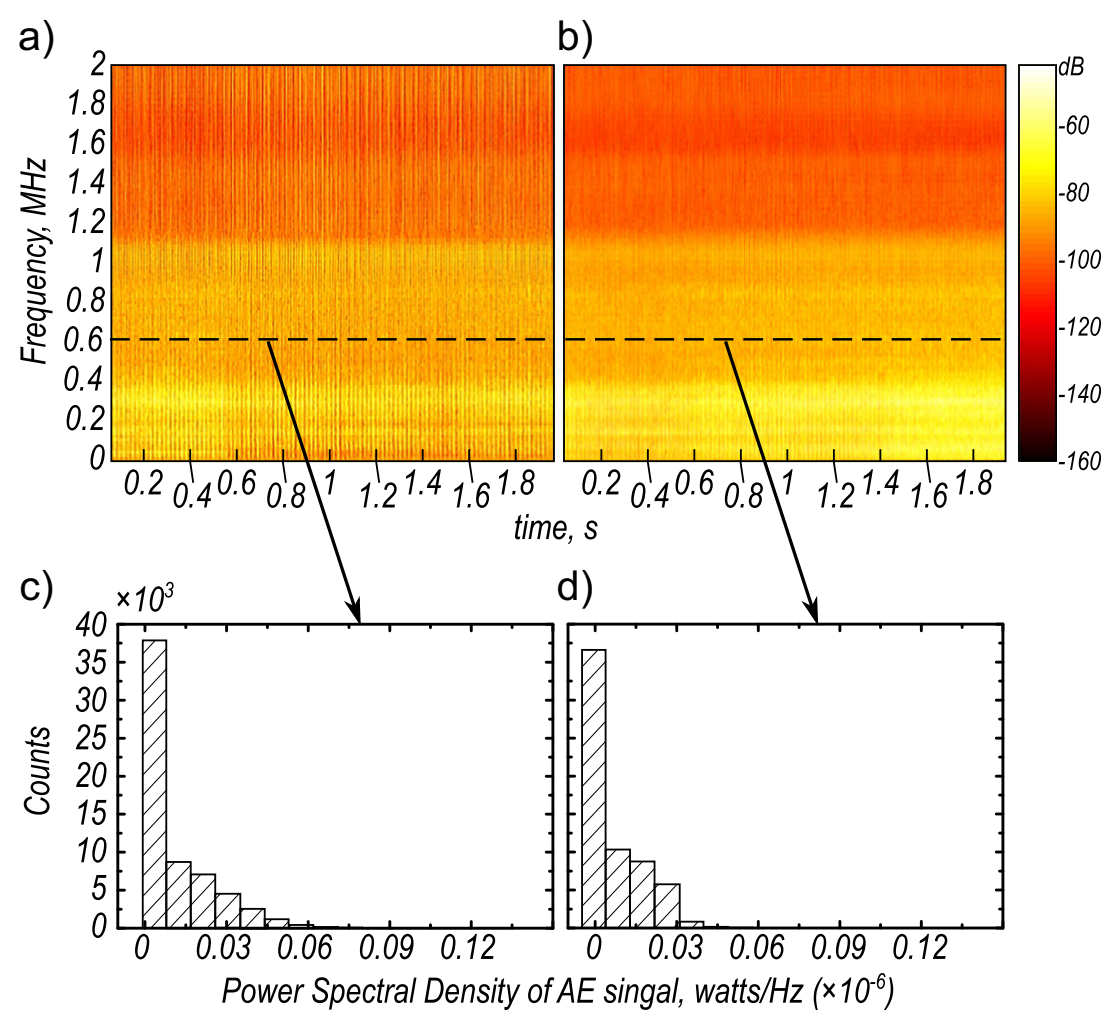

processing of difficult-to-cut materials such as titanium (e.g. reduces friction between abrasive grain and material, removes significantly more heat (and does it more rapidly) than air cooling, prevents heat generation by lubricating the interface between the tool's cutting edge and the chip) [50] and decreases forces in the grinding zone (Fig. 15)). As a result, the sources of AE impulses have lower energy, and therefore the amplitude of $\mathrm{AE}$ [51] decreases and the mean value of power spectral density of signal is reduced (Table 6 and Fig. 18a).

Table 6 Examples of statistical parameters of the power spectral density distribution of the acoustic emission signal recorded under different conditions of grinding

\begin{tabular}{|c|c|c|c|}
\hline \multirow[t]{2}{*}{ Sample code mark } & Mean & Std. deviation & Range \\
\hline & \multicolumn{3}{|c|}{$\mathrm{W} / \mathrm{Hz}\left(\times 10^{-9}\right)$, equiv. $\mathrm{nW} / \mathrm{Hz}$} \\
\hline S1010A-KS-000-00 & 4.7 & 7.2 & 118.0 \\
\hline S1010A-KD-000-00 & 0.5 & 1.0 & 23.7 \\
\hline S1010A-AE-100-08 & 0.2 & 0.3 & 8.1 \\
\hline S1010A-AE-150-12 & 0.3 & 59.3 & 18.7 \\
\hline S1010A-AE-200-25 & 11.3 & 16.4 & 175.2 \\
\hline S1012A-KS-000-00 & 0.7 & 1.1 & 22.5 \\
\hline S1012A-KD-000-00 & 10.6 & 13.5 & 168.1 \\
\hline S1012A-AE-100-08 & 7.3 & 9.2 & 75.6 \\
\hline S1012A-AE-150-12 & 0.9 & 1.8 & 127.5 \\
\hline S1012A-AE-200-25 & 0.8 & 1.0 & 15.4 \\
\hline
\end{tabular}

a)

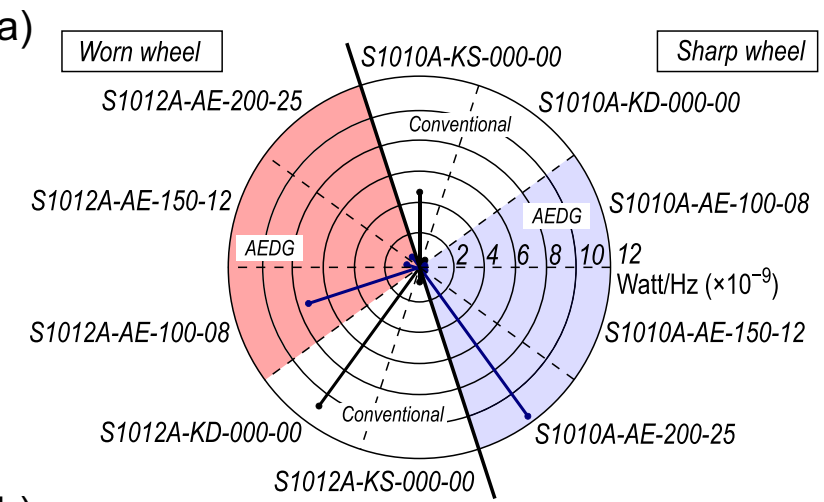

b)

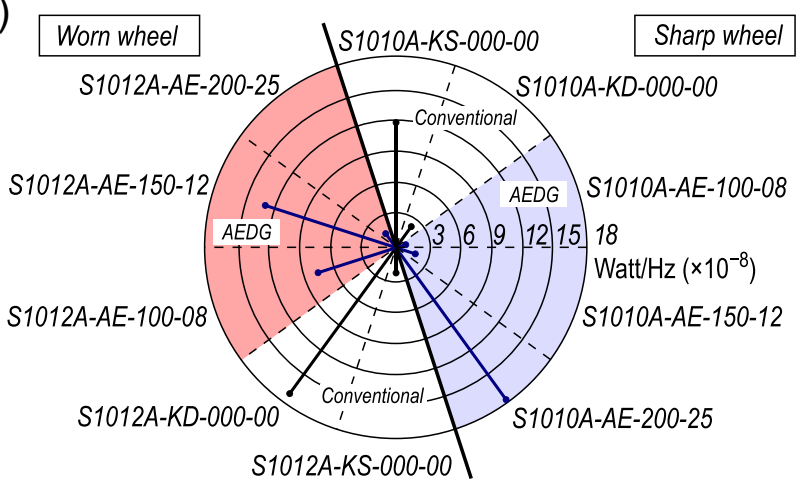

Fig. 18 Radar charts of statistic parameters of PSD values of AE signal for the grinding process conducted with the use of the sharp (S1010A series) and the worn wheel (S1012A series). a Mean value of PSD. b Range of PSD values in signal 
Reverse relationship is observed in the case of use of the worn wheel. The mean value of PSD increases from 0.7 to $10.6 \mathrm{nW} / \mathrm{Hz}$ (cases S1012A-KS-000-00 and S1012A-KD000-00 respectively). Referring to the results of the Nisal study, it can be assumed that this phenomenon was caused by the following factors increasing the amplitude of the $\mathrm{AE}$ signal (in descending order of probability): abrasive wear, failure due to micro-cutting, rough relief, boundary friction with liquid lubricant, high sliding velocity, heavy load [51]. However, clarification of this phenomenon requires further, more detailed research.

Introduction of the low-power electric discharges into the grinding process caused a decrease in the AE signal amplitude, regardless of which, the sharp (from 0.5 to $0.2 \mathrm{nW} / \mathrm{Hz}$ ) or worn wheel (from 10.6 to $7.3 \mathrm{nW} / \mathrm{Hz}$ ), was used. This is due to the nature of the hybrid process. Due to electric discharges, the thermal energy of sparks leads to intense heat flow into the workpiece, causing local melting and partial evaporation of the material. Moreover, removal of the material by individual grains requires much less energy, which translates into a decrease in the recorded $\mathrm{AE}$ values.

Change in discharge voltage and current in the AEDG process caused reduction of mean values of the signal from $11.3 \mathrm{nW} / \mathrm{Hz}$ (S1010A-AE-200-25) to $0.2 \mathrm{nW} / \mathrm{Hz}$ (S1010AAE-100-08) in the case of the sharp wheel and from $7.3 \mathrm{nW} /$ $\mathrm{Hz}$ (S1012A-AE-100-08) to $0.8 \mathrm{nW} / \mathrm{Hz}$ (S1012A-AE-20025 ) in the case of the worn wheel.

The clear trend of changes of analysed values can be observed in the case of range parameter (Fig. 18b). If we compare the sharp wheel with the worn one (opposite sections), we can observe that the use of the worn grinding wheel makes a significant change in the difference between the largest and smallest PSD value. The small range of values in the AE signal spectrum changes to large, and vice versa. This means that if we know the current grinding process parameters (also in case AEDG process), we can very easily determine whether the process is performed with a sharp wheel or a worn one.

\subsection{In-process prediction of the surface quality}

For the assessment of the process in terms of predicting the quality of the ground surface, correlation functions between the measured output signals and the selected parameters of the geometrical structure of the surface were analysed.

The experimental research and analysis of the obtained results proved that for hybrid process (AEDG process in this case), involving multiple sources of AE (including interferences and noise), it is possible to define clear, statistically important correlation of the signal with some surface quality parameters. In the case of components of grinding forces, no statistically significant correlation functions were obtained for the considered range of data.
As a result of those analyses, a set of parameters was distinguished for which it was possible to determine statistically significant models. Table 7 presents examples of correlation functions, for which high coefficients of determination were obtained and the F-Snedecor test exceeds its critical value.

It follows that from the above-presented group of functions, three models with the highest adjustment fitting to experimental data can be selected. The models which are most strongly correlated with the AE signal, and thus can be used for prediction of surface roughness, are those describing the relationships for $S z$ (ten-point height of the surface) and $V v v$ (the void volume of the valley section). Figure 19 shows an exemplary scatter plot with the correlation function and confidence intervals (at the 95\% confidence level) introduced.

In the case of the FLTt flatness parameter, the determined prediction equation has an adjusted coefficient of determination equal to 0.968 (Fig. 20).

The results indicate the possibility of developing a classifier for the AE signal, which can be used to predict the class of the signal, i.e. to make an allocation of the recorded signal to a set of predefined classes (e.g. conditions of the grinding process).

A clear trend line and concentration of measurement data, which determine the accuracy of prediction of a classifier, indicate that the acoustic emission signal is more strongly correlated with the phenomena taking place in the grinding zone than the grinding force components.

\subsection{Prediction of grinding wheel wear}

In order to develop the statistical classifier, the analysis of signals recorded during the grinding process was performed. In the measurements, the grinding force (normal $F_{n}$ and tangential $F_{t}$ components) and the acoustic emission signal (filtered $A E_{\text {filt. }}$ and its effective $E A_{R M S}$ values) were recorded. As

Table 7 The examples of the correlation functions between few parameters of the surface roughness and the acoustic emission signal

\begin{tabular}{lll}
\hline Equitation & $\begin{array}{l}\text { Adj. R- } \\
\text { Square }\end{array}$ & $\begin{array}{l}\mathrm{F} \\
\text { value }\end{array}$ \\
\hline & 0.82 & 298.80 \\
$S z=15.7-7.4 \cdot 10^{-16}\left(\frac{\exp \left(20.1 \cdot A E_{\text {fit. }}\right)-1}{20.1}\right)$ & & \\
$S z=\exp \left(-1.5+2.3 A E_{R M S}-0.3 A E_{R M S}^{2}\right)$ & 0.86 & 397.56 \\
$S a=\exp \left(-3.67+2.2 A E_{R M S}-0.3 A E_{R M S}^{2}\right)$ & 0.60 & 83.49 \\
$S k u=3.7 \cdot \ln \left(2.2 \cdot \ln \left(A E_{R M S}\right)\right)$ & 0.65 & 592.34 \\
$V v v=\exp \left(12.7-6.1 A E_{R M S}+0.7 A E_{R M S}^{2}\right)$ & 0.81 & 39.45 \\
$V m p=\exp \left(16.9-8.7 A E_{R M S}+1.1 A E_{R M S}^{2}\right)$ & 0.65 & 29.72 \\
\hline
\end{tabular}




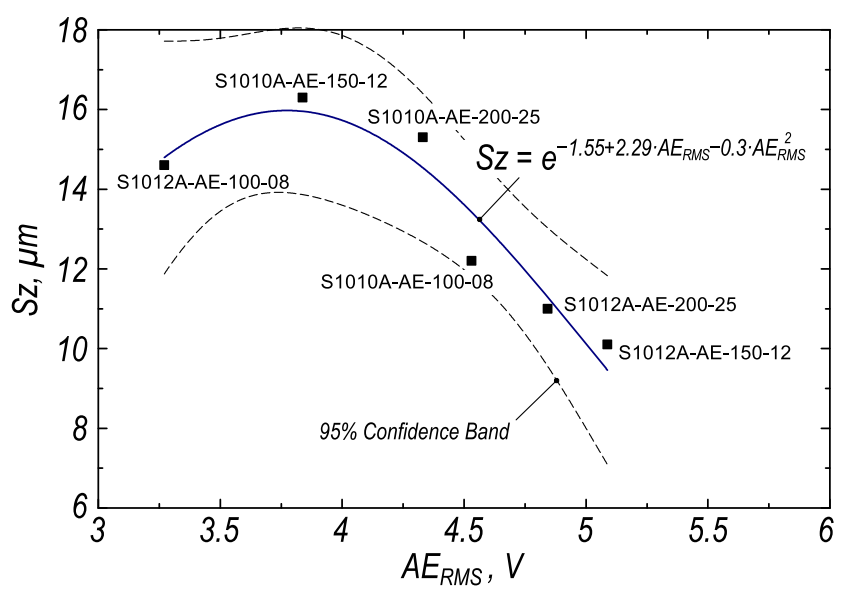

Fig. 19 The correlation between the maximum height of surface roughness $(S z)$ and the effective value of the acoustic emission signal $\left(A E_{R M S}\right)$ for different AEDG process conditions. Note: the goodness of fit is 0.86

dependent quality variables, both the cutting ability of the grinding wheel's active surface (wheel condition) and encoded parameters of AEDG process were considered.

The goodness of fit for predictive classification was evaluated in the Data Miner module of STATISTICA software (StatSoft, Inc., USA). The result of the G-square test (i.e. maximum likelihood Chi-square) for the wheel condition qualitative variable is equal to 41.59 , and the variable encoded parameters is 0 (with critical values 3.84 and 5.99, respectively). This proves statistical significance between input and output variables only in the case of wheel condition qualitative variable.

In the next step, the cluster analysis was performed using $k$ means. This method aims to partition $n$ observations into $k$ clusters (concentrations) so that each observation belongs to the cluster with the nearest mean. Software has correctly

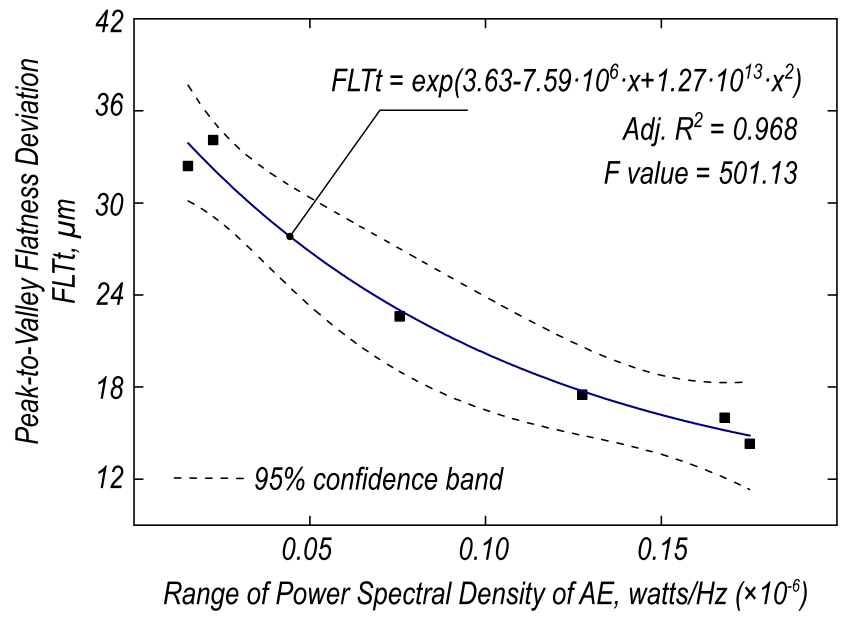

high-worn $\longleftrightarrow$ wheel wear $\longrightarrow$ sharp

Fig. 20 The correlation between the flatness deviation of the surface and the range of the power spectral density of the AE signal identified the input data (the set of independent variables: $A E_{f i l t}, A E_{R M S}, F_{n}$ and $F_{t}$ ) and divided them into two independent clusters. Cluster no. 1 corresponds to grinding with the sharp wheel, cluster no. 2 to grinding with the worn wheel. Figure 21 presents a plot of average values of quantitative variables (the values plotted in figure are scaled relative to all values of these variables) for separated clusters.

The average absolute values of predictors for identified clusters are given in Table 8.

Additionally, the association of attributes of the object with a specified class was made using classification trees. In the case of Random Forest ${ }^{\circledR}$ (algorithm developed by Leo Breiman-[52]), a set of simple trees provides the value of the dependent variable based on values of several predictors (independent variables). Each of the trees forming the Random Forest ${ }^{\circledR}$ uses randomly selected subset of all predictors. The algorithm calculates how many trees indicate the specific class compared to other classes. This allows not only choosing the expected class but also determining the degree of certainty for that prediction (Table 9).

Considering the above results of validity of the predictors and using non-parametric Multivariate Adaptive Regression Splines (MARSplines), a system of equations representing the prediction model of the grinding wheel condition has been developed:

$$
\begin{aligned}
\text { SHARP }= & 8.95 \cdot 10^{-1}-4.26 \cdot 10^{-3} \\
& \times \max \left(0 ; F_{t}-2.64 \cdot 10^{2}\right)-5.57 \cdot 10^{-1} \\
& \times \max \left(0 ; A E_{R M S}-4.4\right) \\
W O R N= & 1.05 \cdot 10^{-1}-4.26 \cdot 10^{-3} \times \max \left(0 ; F_{t}-2.64 \cdot 10^{2}\right) \\
& +5.57 \cdot 10^{-1} \times \max \left(0 ; A E_{R M S}-4,4\right)
\end{aligned}
$$

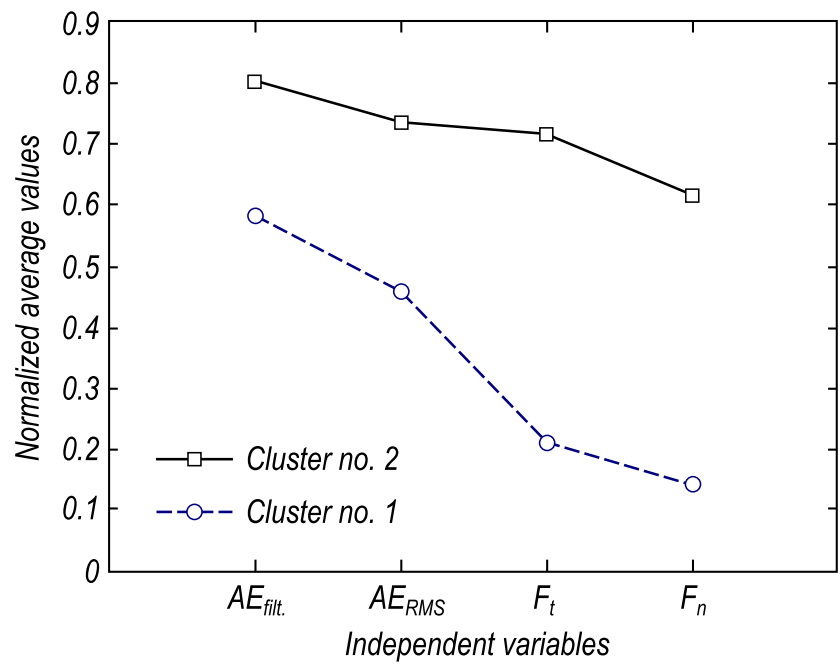

Fig. 21 The plot of normalised average values of quantitative variables for separated clusters obtained with the Data Miner module of STATISTICA software 
Table 8 Average absolute values of predictors for identified clusters

\begin{tabular}{llllll} 
Cluster & Wheel condition & $A E_{\text {filt. }}(\mathrm{V})$ & $A E_{R M S}(\mathrm{~V})$ & $F_{t}(\mathrm{~N})$ & $F_{n}(\mathrm{~N})$ \\
\hline 1 & Sharp & 1.79 & 3.59 & 218.60 & 383.53 \\
2 & Worn & 1.92 & 4.69 & 386.41 & 674.59
\end{tabular}

The 'sharp' and 'worn' conditions are determined by two equations simultaneously in the range of 0 to 1 , e.g. for $A E_{\text {filt. }}=1.6 \mathrm{~V}, A E_{R M S}=3 \mathrm{~V}, F_{n}=240 \mathrm{~N}$ and $F_{t}=420 \mathrm{~N}$, the model defines the wheel as sharp, as can be read from the values: $\mathrm{SHARP}=0.895, \mathrm{WORN}=0.105$.

The accuracy of the model is determined by the generalised cross validation (GCV) error, which takes into account not only the residual sum of squares (RSS) but also the complexity of the model. In the case of Eqs. (1) and (2), GCV is 0.18 (18\%). Thus, taking into account the GCV error, the extreme values of the parameters are SHARP $=0.715, \mathrm{WORN}=0.285$, which does not change the classification decision.

\subsection{AEDG process classifier by SVM}

To classify data using trees and supervised machine learning, the Classifier Leaner (CL) was used. The CL is a Statistic and Machine Learning Toolbox from MATLAB (MatWorks, Inc., USA).

A set of data entered into the classifier included five predictors $\left(A E_{\text {filt. }}, A E_{R M S}, F_{n}, F_{t}\right.$, wheel condition) and one dependent parameter (encoded parameters of AEDG process). Table 10 presents the impact of pruning on the number of inputs that directly reflect the feature selection task and on the classifier accuracy.

The initial structure contained 5/5 features. After $77 \%$ pruning, the number of predictors was reduced to three and the performance increased to $93.3 \%$ (two incorrect predictions per 30 model observations). Further pruning resulted in a fault answers increase, so the structure with $A E_{\text {filt }}, F_{t}$ and $F_{n}$ parameters can be accepted to constitute the final model structure.

The selected structure of the decision tree allows performing relatively precise classification of the AEDG

Table 9 Validity of predictors for wheel condition-dependent variable identified by STATISTICA software using Random Forest ${ }^{\circledR}$ algorithm and MARSplines method

\begin{tabular}{llllll}
\hline Predictor & $A E_{\text {filt. }}$ & $A E_{R M S}$ & $F_{t}$ & $F_{n}$ & AEDG parameters \\
\hline Significance $^{\mathrm{a}}$ & 0.82 & 0.70 & 1.0 & 0.69 & 0.21 \\
Influence $^{\mathrm{b}}$ & 0 & 1 & 1 & 0 & $\mathrm{~N} / \mathrm{A}$ \\
\hline
\end{tabular}

${ }^{\mathrm{a}}$ Random Forest algorithm

${ }^{\mathrm{b}}$ MARSplines method
Table 10 Illustration of the decision tree pruning procedure

\begin{tabular}{lllllll}
\hline $\begin{array}{l}\text { Stage of } \\
\text { pruning }\end{array}$ & \multicolumn{3}{l}{ Input predictors } & & & $\begin{array}{l}\text { Classifier } \\
\text { accuracy } \\
\text { in \%) }\end{array}$ \\
\cline { 2 - 6 } & $A E_{\text {filt. }}$ & $A E_{R M S}$ & $F_{t}$ & $F_{n}$ & $\begin{array}{l}\text { Wheel } \\
\text { condition }\end{array}$ & \\
\hline Initial & - & - & - & - & - & 90.0 \\
$6 \%$ & - & - & - & - & & 90.0 \\
$12 \%$ & - & - & - & & 83.3 \\
$19 \%$ & - & - & & & 73.3 \\
$32 \%$ & & - & - & & 80.0 \\
$58 \%$ & & - & - & - & 86.7 \\
$64 \%$ & - & - & & - & 90.0 \\
$77 \%$ & & - & - & 93.3 \\
\hline
\end{tabular}

process by means of analysing only three factors due to the electrical discharge parameters. The structure of this tree is shown in Fig. 22.

The formed set of rules provides that in the case of $F_{t}<201 \mathrm{~N}$ or $F_{t}>201 \mathrm{~N}$ and simultaneously $F_{n}>826 \mathrm{~N}$, the process will be classified to the group ' 12 ' (that is $150 \mathrm{~V}$ and $12 \mathrm{~A}$ for electrical discharges). If $F_{n}<826 \mathrm{~N}$ and $A E_{\text {filt. }}<1.74 \mathrm{~V}$, the process will be assigned to the group ' 8 ' $(100 \mathrm{~V}, 8 \mathrm{~A})$. If the amplitude of $A E_{\text {filt. }}$ parameter is greater than $1.74 \mathrm{~V}$, the values of grinding force components are reexamined.

The accuracy of the decision tree depends on how well the model separates the group. The accuracy of the developed classifier was measured as an area under the ROC curve (AUC parameter). The observed values for class 8 , class 12 and class 25 are $0.95,1.0$ and 0.95 , respectively. The area over 0.9 represents an excellent test (according to [53, 54]), so the developed classifier can be acknowledged as an expert system.

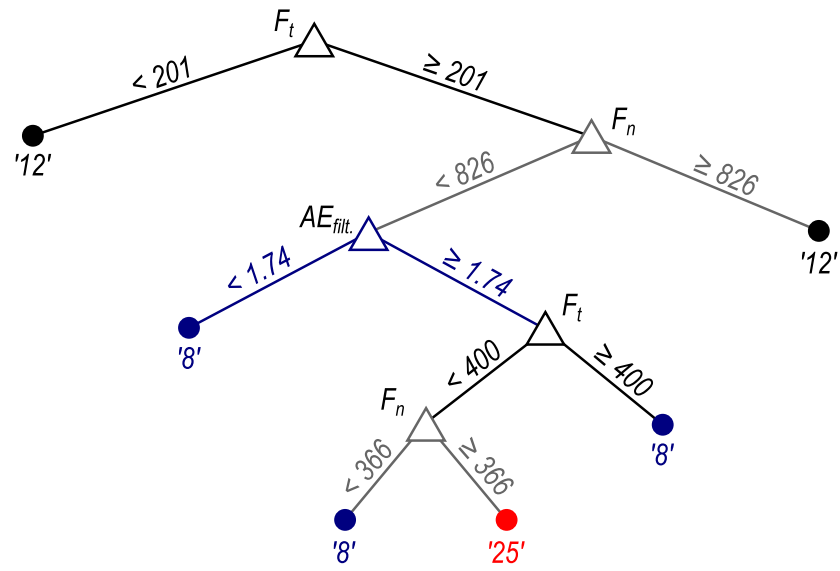

Fig. 22 Decision tree for classification of the AEDG process after reduction to three predictors (accuracy 93.3\%) 


\section{Conclusions and summary}

Experimental studies confirmed that conditions of the grinding process of Ti6Al4V titanium alloy using super hard grinding wheels of metal-bonded cubic boron nitride, including the applied power of generated electric sparks and wear of the active surface of the wheel, have a significant impact on the whole process and its results as well as on the in-process registered values of output signals (acoustic emission and grinding force).

The results can be summarised as follows:

1. The use of grinding wheels with different degrees of wear of the active surface leads to a change in the quality of results of grinding. When a worn wheel is used, the geometrical structure of the workpiece surface has significantly increased flatness deviation and roughness.

2. Depending on the electrical discharge parameters and the grinding wheel wear level, the observed in-process grinding force components and $\mathrm{AE}$ signal change their values in a significant manner.

3. Selected descriptors of the AE signal are strongly related to roughness parameters of the geometric structure of the workpiece surface, which means that the AE signal may be accepted as a good carrier of information about the processes taking place in the area of grinding and is more correlated with machining results than grinding force components.

4. The AEDG process can be assessed and classified with respect to energy of electrical discharges. The high accuracy of the classification to appropriate group is provided by analysing the set of $A E_{\text {filt. }}, F_{n}$ and $F_{t}$ parameters.

5. The cutting ability of the grinding wheel's active surface can be evaluated and identified with high probability as a worn or sharp depending on in-process recorded values of $A E_{R M S}$ and $F_{t}$ parameters.

The results of the experimental research and analysis give grounds to estimate machining results, cutting ability of the grinding wheel and efficiency of the AEDG process in grinding of titanium alloys. In longer term, the results can be used to diagnose and control the process, determining the lifespan of super hard metal-bonded grinding wheels.

Funding This research did not receive any specific grant from funding agencies in the public, commercial, or not-for-profit sectors.

\section{Compliance with ethical standards}

Conflict of interest The authors declare that they have no conflict of interest.

Research involving human participants and/or animals For this type of study, the statement is not applicable.
Informed consent For this type of study, the statement is not applicable.

Open Access This article is distributed under the terms of the Creative Commons Attribution 4.0 International License (http:// creativecommons.org/licenses/by/4.0/), which permits unrestricted use, distribution, and reproduction in any medium, provided you give appropriate credit to the original author(s) and the source, provide a link to the Creative Commons license, and indicate if changes were made.

\section{References}

1. Vinay PV, Rao CS (2013) Grinding mechanics and advances-a review. J Mech Eng Technol 5(2):41-74

2. Li X (2014) Application of self-inhaling internal cooling wheel in vertical surface grinding. Chinese J Mech Eng 27(1):86-91. https:// doi.org/10.3901/CJME.2014.01.086

3. Veiga C, Davim JP, Loureiro AJR (2013) Review on machinability of titanium alloys: the process perspective. Rev Adv Mater Sci 34(2):148-164

4. Vemula VV, Khan TA (2012) Study on grindability of Ti-6Al-4V using solid lubricants. Int J Emerg Technol 3(1):109-114

5. Malkin S, Guo C (2007) Thermal analysis of grinding. CIRP Ann Manuf Techn 56(2):760-782. https://doi.org/10.1016/j.cirp.2007. 10.005

6. Sutowski P, Święcik R (2016) Badania wysokoczęstotliwościowych fal naprężeń w procesie elektroerozyjnego szlifowania stopu tytanu [the study of the high-frequency stress waves in the abrasive electrical discharge grinding of titanium alloy]. Mechanik 89(8-9):1098-1099. https://doi.org/10.17814/mechanik.2016.8-9.266

7. Hood R, Cooper P, Aspinwall DK, Lee DS (2015) Creep feed grinding of $\gamma$-TiAl using single layer electroplated diamond superabrasive wheels. CIRP J Manuf Sci Techol 11:36-44. https://doi.org/10.1016/j.cirpj.2015. 07.001

8. Zhao B, Ding WF, Xu JH, Su HH (2016) Comparative study on cutting behavior of vitrified cubic boron nitride wheel and electroplated cubic boron nitride wheel in high-speed grinding of $\left(\mathrm{TiC}_{\mathrm{p}}+\mathrm{TiB}_{\mathrm{w}}\right) / \mathrm{Ti}-6 \mathrm{Al}-4 \mathrm{~V}$ composites. P I Mech Eng B-J Eng 230(3):428-438. https://doi.org/10.1177/095440541455 3457

9. Li Z, Ding W, Shen L, Xi X, Fu Y (2016) Comparative investigation on high-speed grinding of $\mathrm{TiCp} / \mathrm{Ti}-6 \mathrm{Al}-4 \mathrm{~V}$ particulate reinforced titanium matrix composites with single-layer electroplated and brazed CBN wheels. Chin J Aeronaut 29(5):1414-1424. https://doi.org/10.1016/ j.cja.2016.01.005

10. Xu X, Yu Y, Huang H (2003) Mechanisms of abrasive wear in the grinding of titanium (TC4) and nickel (K417) alloys. Wear 255(712):1421-1426. https://doi.org/10.1016/S0043-1648(03)00163-7

11. Hood R, Aspinwall DK, Voice W (2007) Creep feed grinding of a gamma titanium aluminide intermetallic alloy using $\mathrm{SiC}$ abrasives. J Mater Process Tech 191(1-3):210-214. https://doi.org/10.1016/j. jmatprotec. 2007.03.081

12. Zhang HX, Chen WY, Chen ZT (2007) Experimental studies on grinding of titanium alloy with SG wheels. Key Eng Mater 329:7580. https://doi.org/10.4028/www.scientific.net/KEM.329. 75

13. Nadolny K, Sienicki W, Wojtewicz M (2015) The effect upon the grinding wheel active surface condition when impregnating with non-metallic elements during internal cylindrical grinding of titanium. Arch Civ Mech Eng Arch Civ Mech Eng 15(1):71-86. https:// doi.org/10.1016/ j.acme.2014.03. 004

14. Nadolny K, Kapłonek W, Wojtewicz M, Sienicki W (2013) Effects of sulfurization of grinding wheels on internal cylindrical grinding of titanium grade $2 \circledR$. Indian J Eng Mater S 20(2):108-124 
15. Teicher U, Ghosh A, Chattopadhyay AB, Künanz K (2006) On the grindability of titanium alloy by brazed type monolayered superabrasive grinding wheels. Int J Mach Tool Manu 46(6):620 622. https://doi.org/10.1016/j.ijmachtools.2005.07.012

16. Li X, Chen Z, Chen W (2011) Suppression of surface burn in grinding of titanium alloy TC4 using a self-inhaling internal cooling wheel. Chin J Aeronaut 24(1):96-101. https://doi.org/10.1016/ S1000-9361(11) 60012-5

17. Boswell B, Islam M, Davies IJ, Ginting YR, Ong AK (2017) A review identifying the effectiveness of minimum quantity lubrication (MQL) during conventional machining. Int J Adv Manuf Technol First Online: 23 February 2017. https://doi.org/10.1007/ s00170-017-0142-3

18. Święcik R (2009) Experimental investigation of abrasive electrodischarge grinding of Ti6Al4V titanium alloy. J Achiev Mater Manuf Eng 37(2):706-711

19. Wang Y, Lin B, Cao X, Wang S (2014) An experimental investigation of system matching in ultrasonic vibration assisted grinding for titanium. J Mater Process Technol 214(9):1871-1878. https://doi. org/10.1016/j.jmatpro tec.2014.04.001

20. Razavi HA, Kurfess TR, Danyluk S (2003) Force control grinding of gamma titanium aluminide. Int J Mach Tool Manu 43(2):185191. https://doi.org/10.1016/S0890-6955(02)00113-X

21. Hasçalık A, Çaydaş U (2007) A comparative study of surface integrity of Ti-6Al-4V alloy machined by EDM and AECG. J Mater Process Technol 190(1-3):173-180. https://doi.org/10.1016/ j. jmatprotec.2007.02.048

22. Niemczewska-Wójcik M (2011) Wpływ wybranych parametrów obróbki elektroerozyjnej na cechy powierzchni obrobionej [the influence of the chosen parameters of electric discharge machining on the surface features]. Tribologia 42(6):151-159

23. Amorim F, Weingaertner W (2007) The behavior of graphite and copper electrodes on the finish die-sinking electrical discharge machining (EDM) of AISI P20 tool steel. J Braz Soc Mech Sci 29(4): 366-371. https://doi.org/10.1590/S1678-58782007000400004

24. Gatto A, Sofroniou M, Spaletta G, Bassoli E (2015) On the chaotic nature of electro-discharge machining. Int J Adv Manuf Technol 79(5):985-996. https://doi.org/10.1007/s00170-015-6894-8

25. Yadav SKS, Yadava V, Lakshmi Narayana V (2008) Experimental study and parameter design of electro-discharge diamond grinding. Int J Adv Manuf Technol 36(1):34-4236. https://doi.org/10.1007/ s00170-006-0820-z

26. Kozak J (2002) Abrasive electrodischarge grinding (AEDG) of advanced materials. Arch Civ Mech Eng 2(1-2):83-95

27. Guo G, Liu Z, An Q, Chen M (2011) Experimental investigation on conventional grinding of Ti-6Al-4V using $\mathrm{SiC}$ abrasive. Int J Adv Manuf Technol 57(1):135-142. https://doi.org/10.1007/s00170011-3272-Z

28. Sutowski P, Sutowska M (2017) Kapłonek W (2017) The use of high-frequency acoustic emission analysis for in-process assessment of the surface quality of aluminium alloy 5251 in abrasive waterjet machining. Proc Inst Mech Eng, B J Eng Manuf Online first: April 19. https://doi.org/10.1177/0954405417703428

29. Sutowski P, Nadolny K, Kapłonek W (2012) Monitoring of cylindrical grinding processes by use of a non-contact AE system. Int $\mathrm{J}$ Precis Eng Man 13(10):1737-1743. https://doi.org/10.1007/ s12541-012-0228-7

30. Susic E, Grabec I (2000) Characterization of the grinding process by acoustic emission. Int J Mach Tool Manu 40(2):225-238. https:// doi.org/10.1016/S0890-6955(99) 00055-3

31. Sutowski P (2010) Oszacowanie stopnia zużycia ściernicy z wykorzystaniem sygnału emisji akustycznej i teorii zbiorów rozmytych [the evaluation of grinding wheel wear with use of acoustic emission signal and fuzzy logic system]. Archiwum Technologii Maszyn i Automatyzacji 30(4):47-56
32. Sutowski P (2012) Surface evaluation during the grinding process using acoustic emission signal. Journal of Machine Engineering 12(4):23-34

33. Kwak JS, Ha MK (2004) Neural network approach for diagnosis of grinding operation by acoustic emission and power signals. J Mater Process Technol 147(1):65-71. https://doi.org/10.1016/ j. jmatprotec.2003.11.016

34. Cichon A (2009) The application of the selected time-frequency descriptors detection of the acoustic emission signals generated by multisource partial discharges. Acta Phys Pol A-Opt Acoust Methods Sci Technol 116(3):209-293. https://doi.org/10.12693/ APhysPolA.116.290

35. ASTM F1108-14 (2014) Standard specification for titanium6aluminum-4vanadium alloy castings for surgical implants (UNS R56406). ASTM International, West Conshohocken, PA

36. Campanelli SL, Casalino G, Mortello M, Angelastro A, Ludovico AD (2015) Microstructural characteristics and mechanical properties of Ti6Al4V alloy fiber laser welds. Procedia CIRP, 9th CIRP conference on intelligent computation in manufacturing engineering - CIRP ICME '14, 33:428-433. https://doi.org/10.1016/j.Procir.2015.06.098

37. MatWeb, LLC (2017) MatWeb - the Online Materials Information Resource. http://www.matweb.com/search/DataSheet.aspx? MatGUID=a0655d261898456b958e5f825ae85390\&ckck=1. Accessed 14 January 2017

38. Gołąbczak A, Święcik R, Gołąbczak M, Stańczyk B (2014) Badania porównawcze temperatury warstwy wierzchniej w procesie elektroerozyjnego szlifowania (AEDG) materiałów trudnoobrabialnych [comparative studies of the surface layer temperature during abrasive electrodischarge grinding process (AEDG) of hard machinable materials]. Mechanik 87(8-9):134 137

39. Gołąbczak A, Gołąbczak M, Konstantynowicz A, Święcik R, Galant M (2015) Modeling and experimental investigations of the surface layer temperature of titanium alloys during AEDG processing. Defect Diffus Forum 365:63-70. https://doi.org/10.4028/ www.scientific.net/DDF.365.63

40. Gołąbczak A, Gołąbczak M, Święcik R, Stańczyk B, Kaczmarek D (2015) Dwuparametrowa ocena zdolności skrawnych ściernic supertwardych ze spoiwem metalowym [the two-parameter cutting ability evaluation of superhard grinding wheels with metal bonded]. Mechanik 88(8-9):112-116. https://doi.org/10.17814/mechanik. 2015.8-9.353

41. Gołąbczak A, Gołąbczak M, Konstantynowicz A, Święcik R (2016) Modeling and research of temperature distribution in surface layer of titanium alloy workpiece during AEDG and conventional grinding. Contin Mech Thermodyn 28(6):1781-1789. https://doi. org/10.1007/ s00161-016-0509-y

42. Pragłowska-Ryłko N, Sułowicz M (2015) Zastosowanie ruchomej wartości skutecznej prądu do diagnostyki silników indukcyjnych klatkowych [Application of moving RMS current value in diagnostics of squirrel cage induction motors]. Maszyny Elektryczne Zeszyty Problemowe 106(2):141-146

43. Bin Hasan MMA (2012) Model-free drive system current monitoring: faults detection and diagnosis through statistical features extraction and support vector machines classification. Current based condition monitoring of electromechanical systems. Thesis (Ph.D.). School of Engineering Design and Technology, University of Bradford. URI: http://hdl.handle.net/10454/5732

44. Igba J, Alemzadeh K, Durugbo C, Eiriksson ET (2016) Analysing RMS and peak values of vibration signals for condition monitoring of wind turbine gearboxes. Renew Energy 91:90-106. https://doi. org/10.1016/j.renene.2016.01.006

45. Gołąbczak A, Gołąbczak M, Święcik R, Kaczmarek D (2016) Ocena zdolności skrawnych ściernic supertwardych po obciaganiu wybranymi sposobami elektroerozyjnymi [the assessment of cutting ability of superhard grinding wheels after selected 
electrodischarge dressing methods]. Mechanik 10:1356-1357. https://doi.org/10.17814/mechanik.2016.10.359

46. Tom M, Komatsu T, Kunieda M (2002) Measurement of process reaction force in EDM using Hopkinson bar method. J Jpn Soc Precis Eng 68(6):822-826. https://doi.org/10.2493/jjspe.68.822

47. Zhang Y, Liu Y, Yang S, Ji R, Li Z, Zheng C (2014) Investigation on the influence of the dielectrics on the material removal characteristics of EDM. J Mater Process Technol 214(5):1052-1061. https:// doi.org/10.1016/j.jmatprotec.2013.12.012

48. Korolev SV, Krylov VV (1988) Efficient excitation of Rayleigh waves by a strong shock wave initiated by a spark in air. Sov Tech Phys Lett 14(11):843-845

49. Krylov VV (1992) On the theory of surface acoustic wave generation by electric spark discharge. J Phys D Appl Phys 25(2):155161. https://doi.org/10.1088/0022-3727/25/2/004
50. Marinescu ID, Hitchiner M, Uhlmann E, Rowe WB, Inasaki I (2007) Handbook of machining with grinding wheels. CRC Press, Taylor \& Francis Group ISBN: 978-1-57444-671-5

51. Nisal, TV (2014) Monitoring of surface grinding process using acoustic emission (AE) with emphasis on cutting fluid selection. University of Toledo. Theses and Dissertations. 1800. http://utdr. utoledo.edu/theses-dissertations $/ 1800$

52. Breiman L (2001) Random forests. Mach Learn 45(1):5-32. https:// doi.org/10.1023/a: 1010933404324

53. Fawcett T (2006) An introduction to ROC analysis. In: pattern recognition letters - special issue: ROC analysis in pattern recognition. Elsevier science Inc., New York, NY, USA, 27(8):861-874, ISSN: 0167-8655. https://doi.org/10.1016/j.patrec.2005.10.010

54. The MathWorks, Inc. (2016) Statistics and machine learning toolbox ${ }^{\mathrm{TM}}$. User's guide 